\title{
Projection of future monsoon precipitation over the central Himalayas by CMIP5 models under warming scenarios
}

\author{
Indira Kadel ${ }^{1,2, *}$, Takeshi Yamazaki ${ }^{1}$, Toshiki Iwasaki ${ }^{1}$, Muhammad Rais Abdillah ${ }^{1}$ \\ ${ }^{1}$ Atmospheric Science Laboratory, Department of Geophysics, Graduate School of Science, Tohoku University, \\ 980-8578 Sendai, Japan \\ ${ }^{2}$ Department of Hydrology and Meteorology, Nagpokhari, Naxal, Kathmandu, Nepal
}

\begin{abstract}
The credibility of 38 global climate models (GCMs) participating in the Coupled Model Intercomparison Project Phase 5 (CMIP5) is assessed to simulate the spatiotemporal variability of the summer monsoon season (SMS) precipitation over the central Himalayas in and around Nepal in the present climate (1971-2000). The evolution of precipitation during 3 tridecadal periods of the 21st century (2011-2040, 2041-2070 and 2070-2099) under 2 warming scenarios: representative concentration pathways (RCP) 4.5 and RCP8.5, are analyzed based on the systematically selected best models and their multi-model mean. Most of the models capture the annual cycle. However, most are deficient in their simulation of spatial distribution of SMS mean climatology and interannual variability (IAV). Models consistently project a considerable increase in seasonal mean precipitation in the middle and late 21st century under both warming scenarios. However, there is inconsistency in projections of the change in IAV of seasonal mean precipitation in all future periods. The increase in the seasonal mean is contributed to mainly by intensification of moderate to heavy precipitation events and the enhanced frequency and length of active spells. Increased precipitation could be attributed to the increase in moisture flux convergence and enhanced low level circulation. Inconsistency in the spatial distribution of the future projections of SMS precipitation change by the best models indicates the uncertainty of the projections and suggests careful interpretation of projections is required in the study of regional climate change and its consequences.
\end{abstract}

KEY WORDS: Precipitation extremes - Active and break spells $\cdot$ Climate change $\cdot$ Variability $\mathrm{GCM} \cdot \mathrm{Nepal}$

\section{INTRODUCTION}

Precipitation, a highly variable weather parameter, serves human beings as a primary source of water on Earth. Its benefits and negative effects vary among regions. In the central Himalayas, people depend to a great degree on precipitation for water resources (Chalise 2002), agriculture (Menon 2009), energy, and industrial supplies. Frequently, the residents are adversely affected by precipitation-induced natural hazards such as floods (Mirza 2011, Vellore et al.

${ }^{*}$ Corresponding author: kadelindira@gmail.com
2014, 2016), landslides (Dahal \& Hasegawa 2008, Dahal 2012), and drought (Sigdel \& Ikeda 2010, Wang et al. 2013). Furthermore, the Himalayas are regarded as a 'water tower' housing 3 major river basins, namely the Indus, Ganges and Brahmaputra, which supply water to the huge population of South Asia (Chalise 2002, Mishra 2015). In addition, the Himalayas are a storehouse of biological diversity, home to endangered species, and an extremely important part of the global ecosystem (Beniston 2003). Consequently, it is clear that any changes in the

() The authors 2018. Open Access under Creative Commons by Attribution Licence. Use, distribution and reproduction are unrestricted. Authors and original publication must be credited. 
amount, intensity, and frequency of precipitation can impart considerable economic, social, and ecological costs in the Himalayas and the Indian subcontinent.

According to International Panel on Climate Change (IPCC), warming of the climate system is unequivocal. It is linked predominantly to increased anthropogenic greenhouse gases from human activities (IPCC 2013). Anthropogenic greenhouse gases contribute to global mean surface warming, to change in the global water cycle, to reduction in snow and ice cover, and to changes in climate extremes. Moreover, anthropogenic influence is expected to contribute to increases in atmospheric moisture content and changes in precipitation (IPCC 2013).

The Himalayas constitute a unique geographical mountainous region (Fig. 1) of the world that is extremely sensitive to climate change (Xu et al. 2009). The consequences of climate change have already been noticed, such as an increased number of climatic extremes (Baidya et al. 2008, Karki et al. 2017), reduced snow and ice cover (Ageta et al. 2001, Shrestha \& Aryal 2011), as well as changing precipitation trends (Palazzi et al. 2013, 2015, Wang et al. 2013, Panthi et al. 2015, Roxy et al. 2015), and

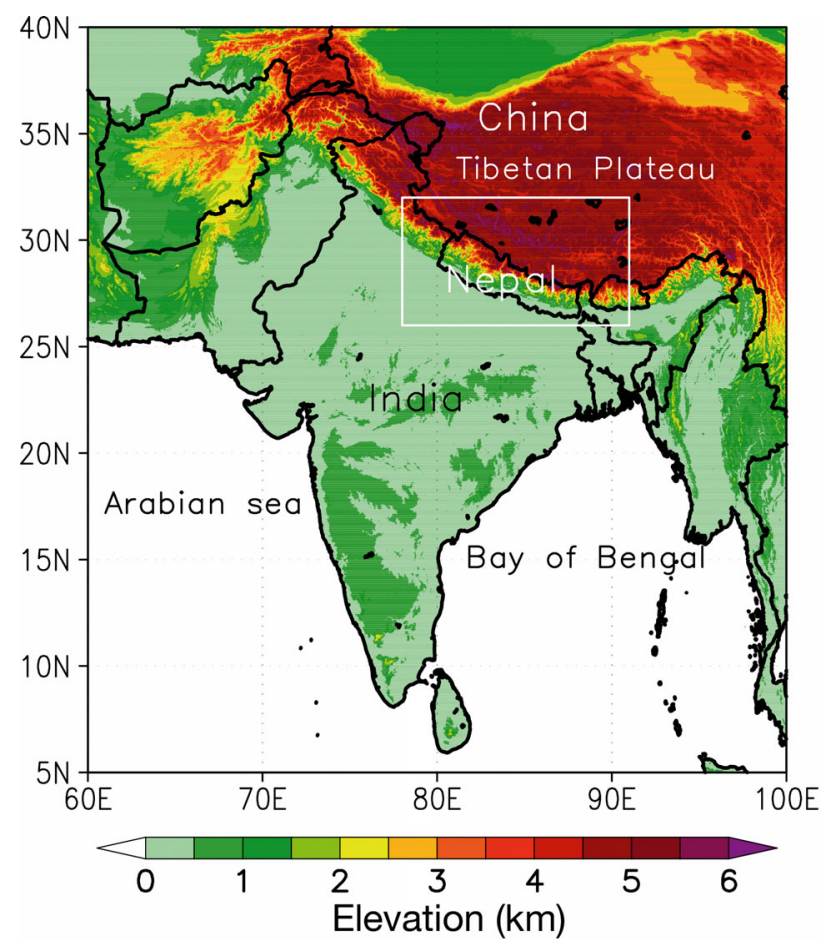

Fig. 1. South Asia, showing location and elevation (above mean sea level) of the study area (white rectangle) for the evaluation of simulated monsoon season precipitation with the present climate, and the analysis of future projection over the the central Himalayan region $(\mathrm{CHR})$ increased variability of precipitation (Duan et al. 2006), particularly over the central Himalaya, Nepal. Consequently, it is essential to understand the future evolution of precipitation under warming climates and to inform policymakers and planners, in order to enable proactive adaptation measures to be taken and ensure sustainable economic development.

In recent decades, global climate models (GCMs) have been widely used to study the response of the global climate system and its components to enhanced anthropogenic gas forcing. Precipitation is an awkward atmospheric variable. Numerical modeling of precipitation presents many challenges. Performance of GCMs is credible at the global scale, and they are able to elucidate large-scale climate features. Nevertheless, GCM performance at the regional scale remains variable (Sperber et al. 2013, Mehran et al. 2014, Ramesh \& Goswami 2014) because of the difficulty of taking into account various factors such as topography, land-cover change, aerosols, and thermodynamic forcing (Turner \& Annamalai 2012, Rajendran et al. 2013). The models' deficiencies are more evident over mountainous regions because of inadequate representation of topographic details and other climate-relevant features such as land cover, which are important determinants of modulating climate in the mountains (Beniston 2003, Duan et al. 2013, Palazzi et al. 2015). Therefore, the performance of a GCM should be evaluated before using its output for regional applications such as the study of regional climate change effects.

The Himalayan region receives about $80 \%$ of its annual total precipitation from the South Asian monsoon system during the months June to September: the summer monsoon season (SMS). The South Asian monsoon can been regarded as a complex, fully coupled ocean-land-atmosphere system (Turner \& Annamalai 2012). Precipitation is highly variable both in space and time. Most GCMs show difficulty in simulating the present South Asian monsoon precipitation climate correctly. Consequently, simulated precipitation is subject to a substantial degree of uncertainty (Webster et al. 1998, Turner \& Annamalai 2012, Sperber et al. 2013). Therefore, the assessment of climate projection reliability poses a major challenge (Ramesh \& Goswami 2014). One widely used approach in handling model uncertainty is to apply a multi-model mean (MMM) for projection analysis. However, MMMs of all available models still embody the uncertainty associated with the models that are incapable of simulating present climate and its variability. Another possible approach is to select models that can simulate the present precipitation climate 
and its spectrum of variability rather than a simple ensemble of all available models (Turner \& Annamalai 2012, Sperber et al. 2013, Ramesh \& Goswami 2014).

Many earlier studies have examined state-of-theart GCM capabilities to simulate historical monsoon precipitation and used selected models to analyze the future evolution in warming scenarios for the Indian subcontinent (e.g. Menon et al. 2013, Sperber et al. 2013, Ramesh \& Goswami 2014, Sharmila et al. 2015). Although the Indian subcontinent, including the Himalayas, receives monsoon season precipitation from the southwest (South Asian) monsoon system, the interannual fluctuations of the monsoon season mean precipitation data over the central Himalayas and over India do not show good agreement, particularly regarding the amplitude of the precipitation (Shrestha et al. 2000). Consequently, with regard to regional climate change perspectives, separate studies of the future evolution of precipitation over the Himalayas must be conducted. However, few studies have addressed the future evolution of Himalayan monsoon precipitation in warming scenarios (Palazzi et al. 2013, 2015, Panday et al. 2015, Rajbhandari et al. 2016). Sharmila et al. (2015) studied performances of $20 \mathrm{GCMs}$ that participated in the Coupled Model Intercomparison Project Phase 5 (CMIP5; Taylor et al. 2012) to simulate daily to interannual variability of monsoon precipitation over the Indian subcontinent, giving priority to precipitation variability over India. Palazzi et al. (2013) investigated the increase in projected monsoon season mean precipitation with an increase in heavy rainfall days over the Himalayas using single-model simulation. Rangwala et al. (2013) reported that a multimodel ensemble of CMIP5 models projects enhanced warming rates in mountains particularly during winter, with the largest increase over the Tibetan Plateau and the Himalayas. Other studies of indices of temperature and precipitation extreme over the western and eastern Himalayas project increases in wet extremes over the eastern Himalayas in future warming scenarios (Panday et al. 2015). Another study by Palazzi et al. (2015) assessed the capabilities of 32 CMIP5 GCMs to simulate the annual cycles of areaaveraged precipitation over the western and central Himalayas. They found that the multi-model ensemble mean and most individual models exhibit a wet bias for all seasons. They classified the models further based on model capabilities, horizontal and vertical resolution, and aerosol representation in the model. Those results revealed that no single model or group of models best represents all precipitation characteristics considered in their study. They also analyzed the future evolution of seasonal mean precipitation, and revealed a wetter future with a gradual increase in summer monsoon rainfall over the central Himalayas in future warming scenarios (Palazzi et al. 2015). A recent study of climate change in a river basin in the Himalayas using statistically downscaled data from 8 CMIP5 GCMs revealed a $14 \%$ increase in SMS precipitation by 2050 (Rajbhandari et al. 2016). Similarly, a very recent study by Wu et al. (2017) investigated the changes projected in mean and extreme climates over Hindu Kush Himalayan region by 21 CMIP5 models and reported that the precipitation extremes are projected to intensify in future over the region. Studies on the evaluation of state-of-the-art GCM capabilities to simulate spatial and temporal variation of SMS precipitation over the central Himalayas as a whole remain insufficient.

This study assesses the capability of CMIP5 GCMs to reproduce spatial and temporal variability of central Himalayan SMS precipitation in the present climate. It responds to concerns regarding high spatiotemporal variation of precipitation in the Himalayas and its consequent effects on the socioeconomy of the region. We investigate future spatial and temporal changes in the mean and variability of SMS precipitation under warming climates based on systematically selected best models and their MMM, rather than a using simple multi-model ensemble of all available models. To date, there are no studies documented that examine the central Himalayas using models that can simulate spatiotemporal variability in present climate. This study is designed to yield valuable results that are useful to ascertain a model's ability for the present condition, and to elucidate the changes expected to occur in the future. Furthermore, knowledge related to model ability is valuable for researchers in selecting a suitable global model to use in regional applications. For example, information related to the ability of GCMs to simulate the present climate helps a regional climate modeler in making GCM model choices for the generation of climate projections on a regional scale. In addition, this study provides opportunities for model developers to build on inherent strengths or address deficiencies in successive generations of these global models.

Although many factors such as model resolution and physical parameterizations affect model performance, and many variables modulate the variability of monsoon rainfall, we only evaluate simulated precipitation. Assessing model capabilities and deficiencies in the simulation of all elements of monsoon 
systems, is beyond the scope of this study. However, this study provides some valuable information related to GCM performance over a mountainous region.

\section{STUDY AREA, DATA AND METHODOLOGY}

\subsection{Study area}

The central Himalayas are the world's most complex region in terms of topography, an area where elevations range from below $100 \mathrm{~m}$ to the 'top of the world' (the summit of Mt. Everest at $8848 \mathrm{~m}$ above sea level) (Fig. 1). The complex topography of the region plays a crucially important role in determining patterns of local wind circulation and precipitation (Lang \& Barros 2002, Barros et al. 2004, Anders et al. 2006). Precipitation throughout the region varies both temporally and spatially. The region receives about 50 to $90 \%$ of total annual precipitation from the SMS (Nayava 1980). Comparison shows that SMS precipitation is greater in southeastern parts than in northwestern parts of the region, while northwestern areas receive considerable amounts of precipitation during winter (December-February) from western disturbance systems (Nayava 1980).

SMS precipitation over the central Himalayas, particularly over Nepal and surrounding areas, is highly correlated with the southern oscillation index (SOI) at an interannual time scale (Shrestha 2000, Shrestha et al. 2000, Sigdel \& Ikeda 2012). In this study, the study area is designated based on the correlation of SMS mean precipitation anomaly in the Himalayan region with mean sea surface temperature (SST) averaged over the Niño3.4 region $\left(5^{\circ} \mathrm{N}\right.$ to $5^{\circ} \mathrm{S}, 120^{\circ}$ to $\left.170^{\circ} \mathrm{W}\right)$ in the Pacific Ocean. The correlation was found to be significant over $26^{\circ}$ to $32^{\circ} \mathrm{N}$ latitude and $78^{\circ}$ to $91^{\circ} \mathrm{E}$ longitude (Fig. 2a). The precipitation over this region is also highly correlated with the SMS mean wind speed at $200 \mathrm{hPa}$ averaged over the Arabian Sea and central India $\left(18^{\circ}\right.$ to $25^{\circ} \mathrm{N}, 60^{\circ}$ to $80^{\circ} \mathrm{E}$ ) (Fig. 2b). Therefore, this area was selected for the study. It is referred to as the central Himalayan region (CHR) hereinafter. The SST, circulation and precipitation datasets used in demarcation of the study area are Extended Reconstructed Sea Surface Temperature version 3b (ERSST3b; Smith et al. 2008), the Japanese 55-year Reanalysis (JRA55; Kobayashi et al. 2015) and Asian Precipitation Highly Resolved Observational Data Integration Towards the Evaluation of Water Resources version 1101 (APHRODITE; Yatagai et al. 2012).
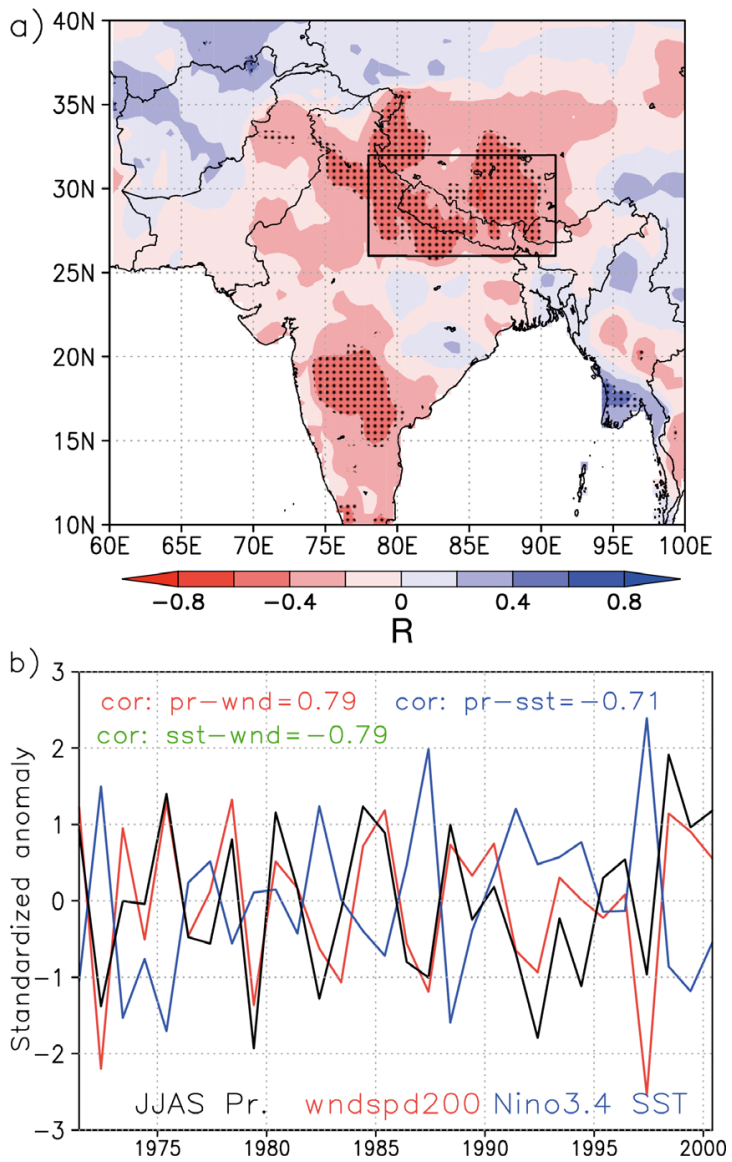

Fig. 2. (a) Spatial distribution of Pearson's correlation coefficient of summer monsoon season (SMS) mean sea surface temperature (SST) over the Nino3.4 region $\left(5^{\circ} \mathrm{N}\right.$ to $5^{\circ} \mathrm{S}, 120^{\circ}$ to $170^{\circ} \mathrm{W}$ ) with SMS mean precipitation anomaly. The stippled areas are significant at the $95 \%$ confidence level. (b) Normalized time series of SMS mean precipitation over the central Himalayan region (black), SMS mean wind speed at $200 \mathrm{hPa}$ averaged over the Arabian Sea and central India $\left(18^{\circ}\right.$ to $25^{\circ} \mathrm{N}, 60^{\circ}$ to $80^{\circ} \mathrm{E}$ ) (red) and SMS mean SST averaged over the Nino3.4 region (blue). Correlation coefficients of SST, wind, and precipitation are given at the top of the figure

\subsection{Observational datasets}

Precipitation over the Himalayas exhibits significant spatial and temporal variations (Lang \& Barros 2002, Barros et al. 2004, Anders et al. 2006). Existing rain-gauge networks are not sufficiently dense to reveal variability at a fine spatial scale. The gauge network density is low in the middle and high mountains because of the high elevation, severe weather, and remoteness of the regions. Since most raingauge stations were established in the 1970s and 1980s (Karki et al. 2017), information on the longterm pattern of precipitation over the CHR is limited. 
Several gridded precipitation datasets derived from ground and/or satellite observations or reanalysis data are now available at varying temporal and spatial resolutions. A major difficulty related to evaluation of models is that these datasets are mutually inconsistent and are adversely affected by imperfect representation of observations (Collins et al. 2013, Mishra 2015). Many researchers have concluded that gauge-based gridded precipitation datasets are better for analyses of the Himalayan regions than satellite and reanalysis datasets (Andermann et al. 2011, Tong et al. 2014, Prakash et al. 2015). However, considerable discrepancies do exist among gauge-based precipitation datasets (Collins et al. 2013, Palazzi et al. 2013, 2015, Mishra 2015). The accuracy of the gauge-based gridded data depends on the number of gauges, interpolation techniques, and climatology used (Yatagai et al. 2012).

In this study, 4 gauge-based gridded precipitation datasets viz. APHRODITE version 1101 (Yatagai et al. 2012), Global Precipitation Climatology Centre (GPCC) full-data version 6 (Schneider et al. 2014), Climatic Research Unit (CRU) version TS3.22 (Harris et al. 2014) and Climate Prediction Center (CPC) version 1.0 (Chen et al. 2002) (Table 1) are used to quantify the observational uncertainty over the study area. All these datasets are available at $0.5^{\circ}$ horizontal resolutions and at monthly timescale except APHRODITE which is available at daily timescale. Brief descriptions of the datasets are given in Table 1. The main differences among these datasets are the number of rain gauges, the interpolation algorithms, and the climatology used. Himalayan regions have sparse gauge networks that certainly influence the quality of gridded precipitation datasets. APHRODITE has incorporated as many stations as possible in order to create representative precipitation datasets (Yatagai et al. 2012), and has been reported to be the best among the gridded datasets (Andermann et al. 2011, Yatagai et al. 2012, Tong et al. 2014, Prakash et al. 2015) for the CHR. Since model performance is sensitive to the choice of ref-

Table 1. Gauge-based gridded precipitation datasets used for this study, with their respective resolution, source, available period and reference

\begin{tabular}{|lccl|}
\hline Dataset & $\begin{array}{c}\text { Spatial/temporal } \\
\text { resolution }\end{array}$ & $\begin{array}{c}\text { Available } \\
\text { period }\end{array}$ & Reference \\
\hline APHRODITE v1101 & $0.5^{\circ} \times 0.5^{\circ}$ /daily & $1951-2007$ & Yatagai et al. (2012) \\
GPCC Full-data v6 & $0.5^{\circ} \times 0.5^{\circ} /$ monthly & $1901-2010$ & Schneider et al. (2014) \\
CRU Ts3.22 & $0.5^{\circ} \times 0.5^{\circ}$ monthly & $1901-2013$ & Harris et al. (2014) \\
CPC v1.0 & $0.5^{\circ} \times 0.5^{\circ} /$ monthly & $1948-$ present & Chen et al. (2002) \\
\hline
\end{tabular}

erence data, APHRODITE is selected as a reference dataset for this study. Many recent studies (Jourdain et al. 2013, Toreti et al. 2013, Mishra et al. 2014) have also used APHRODITE data to evaluate GCM performance.

\subsection{Model data}

Monthly mean precipitation simulated by 38 stateof-the-art GCMs participated in CMIP5 are used to evaluate the model performance in simulating current climatology. Although the simulation period is approximately 1850-2005 for historical runs, evaluations are performed for the period 1971-2000, corresponding to the temporal coverage of the observation network over the study region. To assess changes in the mean state and variability of precipitation in future periods, projections of precipitation under warming scenarios are analyzed for 3 tri-decadal periods in the 21st century: 2011-2040, 2041-2070, and 2070-2099 (hereinafter near-, mid- and farfuture, respectively). Projection data for 2 warming scenarios, Representative Concentration Pathways (RCP) 4.5 and 8.5, are used. Models are selected based on the availability of RCP4.5 and RCP8.5 scenario data. Because of the unavailability of the multiple ensemble runs for all models, we used monthly precipitation of each model from one ensemble member (r1i1p1) for all study periods. To investigate the associated change in atmospheric variables with the change in precipitation, we also analyzed the wind, temperature, specific humidity, and vertical velocity.

Additionally, we analyzed daily precipitation simulation (for ensemble r1i1p1) by the selected best models to investigate change in daily precipitation frequency, and active and break spells under RCP8.5. All model outputs are freely available at the Earth System Grid Federation (ESGF) archive through ESGF data portals (http://cmip-pcmdi.llnl. gov/cmip5/data_getting_started.html). Brief information of CMIP5 models used for this study is presented in Table 2. Some of these models share their model components, such as the atmospheric model, or the ocean model. The analysis of genealogy of the models is available in Knutti et al. (2013). Additional details of models and experiments are available in a report by Taylor et al. (2012), and online at https://pcmdi.llnl. gov/index.html. 


\subsection{Methodology}

\subsubsection{Evaluation and selection of best models}

To evaluate the model capabilities against the observations, all datasets are regridded to common resolution $\left(0.5^{\circ} \times 0.5^{\circ}\right)$ of the reference data using bilinear interpolation, which is a common regridding technique (e.g. Lin et al. 2014, Mishra et al. 2014, Sharmila et al. 2015).

Table 2. CMIP5 models used for this study with their respective horizontal and vertical resolution of atmosphere (AGCM) and ocean (OGCM) general circulation models. N: reduced gaussian grid (N96 is roughly equivalent to $1.25^{\circ}$ latitude $\times 1.875^{\circ}$ longitude). L: vertical levels (L38 means there are 38 vertical levels in a model). T: spectral model (T42 is roughly equivalent to $2.8^{\circ}$ latitude $\times 2.8^{\circ}$ longitude). C: cubed-sphere resolution (C48 is roughly equivalent to $2^{\circ} \times 2^{\circ}$

\begin{tabular}{|c|c|c|}
\hline CMIP5 model & AGCM resolution & OGCM resolution \\
\hline ACCESS1.0 & N96 L38 & $1^{\circ} \times 0.33-1^{\circ} \mathrm{L} 50$ \\
\hline ACCESS1.3 & N96 L38 & $1^{\circ} \times 0.33-1^{\circ} \mathrm{L} 50$ \\
\hline BCC-CSM1.1 & T42 L26 & $1^{\circ} \times 0.33-1^{\circ} \mathrm{L} 40$ \\
\hline BCC-CSM1.1m & T106 L26 & $1^{\circ} \times 0.33-1^{\circ} \mathrm{L} 40$ \\
\hline BNU-ESM & T42 L26 & $1^{\circ} \times 0.33-1^{\circ} \mathrm{L} 50$ \\
\hline CCSM4 & $1.25^{\circ} \times 0.9^{\circ} \mathrm{L} 26$ & $1.125^{\circ} \times 0.27-0.54^{\circ} \mathrm{L} 60$ \\
\hline CESM1-BGC & $1.25^{\circ} \times 0.9^{\circ} \mathrm{L} 26$ & $1.0^{\circ} \times 1.0^{\circ} \mathrm{L} 60$ \\
\hline CESM1-CAM5 & $1.25^{\circ} \times 0.9^{\circ} \mathrm{L} 30$ & $1.125^{\circ} \times 0.27-0.54^{\circ} \mathrm{L} 60$ \\
\hline CMCC-CM & T159 L31 & $2^{\circ} \times 0.5-2^{\circ} \mathrm{L} 31$ \\
\hline CMCC-CMS & T63 L95 & $2^{\circ} \times 0.5-2^{\circ} \mathrm{L} 31$ \\
\hline CNRM-CM5 & T127 L31 & $1.0^{\circ} \times 0.33-1.0^{\circ} \mathrm{L} 42$ \\
\hline CSIRO-Mk3.6.0 & T63 L18 & $1.875^{\circ} \times 0.9375^{\circ} \mathrm{L} 31$ \\
\hline CanESM2 & T63 L35 & $1.41^{\circ} \times 0.94^{\circ} \mathrm{L} 40$ \\
\hline EC-EARTH & T159 L62 & $1.0^{\circ} \times 0.33-1.0^{\circ} \mathrm{L} 42$ \\
\hline FGOALS-g2 & $2.8125^{\circ} \times 2.8125^{\circ} \mathrm{L} 26$ & $1^{\circ} \times 0.5-1^{\circ} \mathrm{L} 30$ \\
\hline FIO-ESM & T42 L26 & $1.125^{\circ} \times 0.27-0.64^{\circ} \mathrm{L} 40$ \\
\hline GFDL-CM3 & C48 L48 & $1.0^{\circ} \times 0.33-1.0^{\circ} \mathrm{L} 50$ \\
\hline GFDL-ESM2G & $2.5^{\circ} \times 2.0^{\circ} \mathrm{L} 24$ & $1.0^{\circ} \times 0.33-1.0^{\circ} \mathrm{L} 63$ \\
\hline GFDL-ESM2M & $2.5^{\circ} \times 2.0^{\circ} \mathrm{L} 24$ & $1.0^{\circ} \times 0.33-1.0^{\circ} \mathrm{L} 50$ \\
\hline GISS-E2-H & $2.5^{\circ} \times 2.0^{\circ} \mathrm{L} 40$ & $1^{\circ} \times 0.2-1^{\circ} \mathrm{L} 26$ \\
\hline GISS-E2-H-CC & $2.5^{\circ} \times 2.0^{\circ} \mathrm{L} 40$ & $1^{\circ} \times 0.2-1^{\circ} \mathrm{L} 26$ \\
\hline GISS-E2-R & $2.5^{\circ} \times 2.0^{\circ} \mathrm{L} 40$ & $1.25^{\circ} \times 1^{\circ} \mathrm{L} 32$ \\
\hline GISS-E2-R-CC & $2.5^{\circ} \times 2.0^{\circ} \mathrm{L} 40$ & $1.25^{\circ} \times 1^{\circ} \mathrm{L} 32$ \\
\hline HadGEM2-AO & N96 L60 & $1^{\circ} \times 0.33-1^{\circ} \mathrm{L} 40$ \\
\hline HadGEM2-CC & N96 L60 & $1^{\circ} \times 0.33-1^{\circ} \mathrm{L} 63$ \\
\hline HadGEM2-ES & N96 L38 & $1^{\circ} \times 0.33-1^{\circ} \mathrm{L} 40$ \\
\hline INMCM4 & $2^{\circ} \times 1.5^{\circ} \mathrm{L} 21$ & $1^{\circ} \times 0.5^{\circ} \mathrm{L} 40$ \\
\hline IPSL-CM5A-LR & $3.75^{\circ} \times 1.875^{\circ} \mathrm{L} 39$ & $2.0^{\circ} \times 0.5-2.0^{\circ} \mathrm{L} 31$ \\
\hline IPSL-CM5A-MR & $2.5^{\circ} \times 1.25^{\circ} \mathrm{L} 39$ & $2.0^{\circ} \times 0.5-2.0^{\circ} \mathrm{L} 31$ \\
\hline IPSL-CM5B-LR & $3.75^{\circ} \times 1.875^{\circ} \mathrm{L} 39$ & $2.0^{\circ} \times 0.5-2.0^{\circ} \mathrm{L} 31$ \\
\hline MIROC5 & T85 L40 & $1.4^{\circ} \times 0.5-1.4^{\circ} \mathrm{L} 50$ \\
\hline MIROC-ESM & T42 L80 & $1.4^{\circ} \times 0.5-1.7^{\circ} \mathrm{L} 44$ \\
\hline MIROC-ESM-CHEM & T42 L80 & $1.4^{\circ} \times 0.5-1.7^{\circ} \mathrm{L} 44$ \\
\hline MPI-ESM-LR & T63 L47 & GR15L40 \\
\hline MPI-ESM-MR & T63 L95 & TP04 L40 \\
\hline MRI-CGCM3 & TL159 L48 & $1.0^{\circ} \times 0.5^{\circ} \mathrm{L} 51$ \\
\hline NorESM1-M & $2.5^{\circ} \times 1.9^{\circ} \mathrm{L} 26$ & $1.125^{\circ} \times 1.125^{\circ} \mathrm{L} 53$ \\
\hline NorESM1-ME & $2.5^{\circ} \times 1.9^{\circ} \mathrm{L} 26$ & $1.125^{\circ} \times 1.125^{\circ} \mathrm{L} 53$ \\
\hline
\end{tabular}

Ranking the GCM performance is an enormously difficult exercise. Several techniques and measures have been used to evaluate GCM performance (e.g. Chadwick et al. 2013, Kumar et al. 2013, Sperber et al. 2013, Mehran et al. 2014, Palazzi et al. 2015, Sharmila et al. 2015), but no individual evaluation technique or performance measure is regarded as a superior one. Many previous studies have used Taylor diagrams (Taylor 2001) to evaluate GCM capabilities to simulate precipitation and other variables (e.g. Inoue \& Ueda 2011, Ogata et al. 2014, Sharmila et al. 2015). These diagrams are suitable for evaluating multiple aspects of climate models because they provide a succinct statistical summary of how closely a pattern of a test variable matches reference variables in terms of their correlation coefficient (CC), centered root-mean-square difference (RMSD) and the ratio of their variations (Taylor 2001). For this study, we used a normalized Taylor diagram in which the radial distance from the origin indicates the normalized standard deviation (NSD) of the variable and the azimuthal position gives the CC between test and reference variables. Similarly, the distance between the test and reference variable indicates the normalized centered RMSD (NRMSD). A model is considered reliable if the test variable lies close to the reference variable in the diagram. For clear scientific analysis, we have defined criteria such that a model is regarded as 'reliable' if $\mathrm{CC} \geq 0.6,0.5 \leq \mathrm{NSD} \leq 1.5$ and NRMSD $\leq 1.0$.

The mean monsoon precipitation and circulation influence the monsoon variability on all timescales. Such variability cannot be simulated correctly without correct representation of the mean state and seasonal cycle (Sperber \& Palmer 1996, Turner et al. 2005, Annamalai et al. 2007). Therefore, Taylor diagrams are constructed for 3 metrics: (1) the spatial pattern of SMS mean precipitation climatology, (2) the annual cycle of area averaged precipitation, and (3) the spatial pattern of interannual variability (IAV) of precipitation. IAV is measured by the interannual standard deviation of SMS mean pre- 
cipitation. Finally, the best models are selected. We regard a model as 'superior' if it is reliable for simulating all 3 metrics.

\subsubsection{Assessment of future change}

After selecting the best models, we constructed a time series of the MMM of monthly precipitation by assigning equal weight to each of the best models. Based on best models and their MMM, the future evolution of precipitation is analyzed.

In this study, changes in mean and IAV of SMS precipitation under 2 warming scenarios, RCP4.5 and RCP8.5, are assessed for near-, mid-, and far-future periods relative to the present climatology. The changes in mean $\left(\overline{\mathrm{P}}_{\text {change }}\right)$ and IAV $\left(\sigma_{\text {change }}\right)$ are computed as:

and:

$$
\overline{\mathrm{P}}_{\text {change }}=100 \times\left(\frac{\overline{\mathrm{P}}_{\text {Future }}-\overline{\mathrm{P}}_{\text {Present }}}{\overline{\mathrm{P}}_{\text {Present }}}\right)
$$

$$
\text { where: } \quad \begin{aligned}
\sigma_{\text {change }}= & 100 \times\left(\frac{\sigma_{\text {Future }}-\sigma_{\text {Present }}}{\sigma_{\text {Present }}}\right) \\
& \overline{\mathrm{P}}=\frac{1}{\mathrm{~N}} \sum_{i=1}^{\mathrm{N}} \mathrm{P}_{i}
\end{aligned}
$$

and:

$$
\sigma=\sqrt{\frac{1}{\mathrm{~N}} \sum_{i=1}^{\mathrm{N}}\left(\mathrm{P}_{i}-\overline{\mathrm{P}}\right)^{2}}
$$

In those equations, $\mathrm{P}_{i}$ is the June-September mean precipitation in the $i$ th year $(i=1,2,3, \ldots, N)$, where $\mathrm{N}$ is the total number of years used for analysis. 'Present' is the present period (1971-2000). 'Future' signifies future periods $(2010-2040,2041-2070$ and 2070-2099).

In addition, the change in annual cycle is investigated based on the daily climatological mean of first 3 harmonics under both warming scenarios. Changes in the frequency of light, moderate, and heavy (1-10, $10-40$ and $>40 \mathrm{~mm} \mathrm{~d}^{-1}$, respectively) precipitation days in future periods under RCP8.5 scenario are also analyzed.

Reportedly, IAV of monsoon precipitation is related significantly to monsoon active and break spells (Krishnamurthy \& Shukla 2000). Long break spells are also known to affect agricultural production (Gadgil \& Joseph 2003). Therefore, changes in active and break spell characteristics are analyzed. To identify the active and break spells, a rainfall index (RI) is created by application of a 9 to $90 \mathrm{~d}$ bandpass filter to the daily area-averaged $\left(26^{\circ}\right.$ to $30^{\circ} \mathrm{N}, 80^{\circ}$ to $\left.89^{\circ} \mathrm{E}\right)$ precipitation anomaly computed by subtracting the climatological mean of the first 3 harmonics. Spec- trum analysis was conducted to ascertain the dominant periodicity of the 9-90 d period used in filtering the detrended anomaly. The standard deviation of RI is computed for each year. Then the climatological mean of the standard deviation $\left(\mathrm{RI}_{\mathrm{std}}\right)$ is computed. Then, active (break) spells are identified for all years, defined as periods when $\mathrm{RI} \geq+1.0(\leq-1.0) \mathrm{RI}_{\text {std }}$ for $\geq 3$ consecutive days or more (Fig. 3a). During active (break) spells of monsoon in the CHR, the precipitation anomaly is positive (negative) in foothills of the Himalayas (Fig. 3b,c). This spatial pattern of precipitation anomaly agrees well with the findings of previous studies on the Indian monsoon that precipitation is excess (deficit) in the foothills of the Himalayas during the break (active) spells in central India (Krishnamurthy \& Shukla 2000, Gadgil \& Joseph 2003, Rajeevan et al. 2010, Goswami 2011).

\section{RESULTS}

\subsection{Evaluation of model performance and selection of the best models}

In this study, performances of 38 GCMs (Table 2) are evaluated relative to the APHRODITE dataset for simulating CHR SMS precipitation for the present climate (1971-2000) by constructing Taylor diagrams for all 3 metrics: (1) annual cycle, (2) spatial pattern of SMS mean precipitation climatology, and (3) spatial pattern of IAV of SMS mean precipitation (Fig. $4 a-$ C).

All the models reproduced annual cycles of mean precipitation over the CHR more or less accurately with CC >0.6, except IPSL-CM5B-LR (-0.24) (Fig. 4a). However, only about half of the models (ACCESS1.3, BCC-CSM1.1, BCC-CSM1.1m, CMCC-CM, CMCCCMS, CNRM-CM5, CSIRO-Mk3.6.0, CanESM2, ECEARTH, FIO-ESM, GFDL-CM3, HadGEM2-ES, INMCM4, IPSL-CM5A-LR, IPSL-CM5A-MR, MIROCESM, MIROC-ESM-CHEM and MRI-CGCM3) are reliable. CNRM-CM5 and the multi-model mean of all 38 models (MMM38) are very close to reference dataset. Although observational datasets (CPC, CRU and GPCC; solid black symbols in Fig. 4a) have slightly higher NSD than the reference dataset, their skills in reproducing the annual cycle are consistent with each other

Results showed that simulating the spatial pattern of monsoon precipitation climatology over the complex terrain presented a major challenge for the models. They generally fail to capture observed topographically driven variability in the study region. Of the $38 \mathrm{GCMs}$, only 10 are reliable, i.e. reproduce rea- 
(a) Daily precipitation (1981)

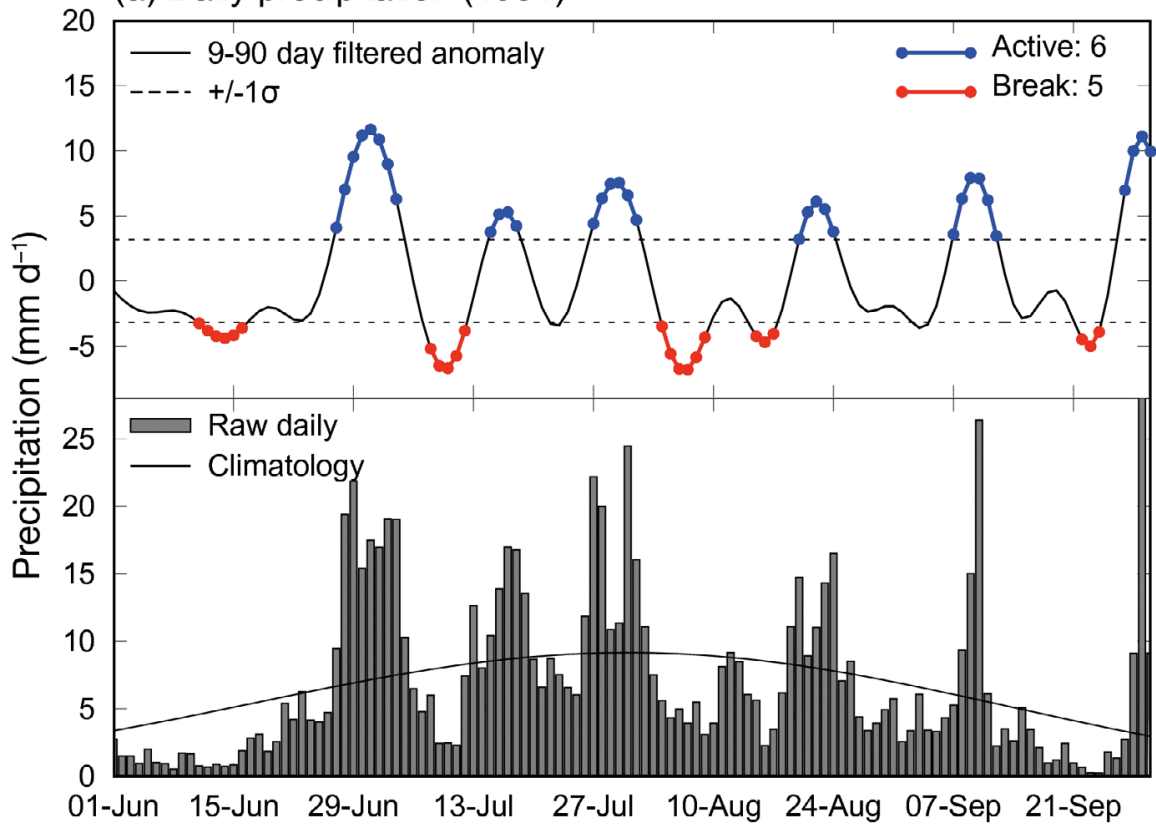

(b) Active (1971-2000)

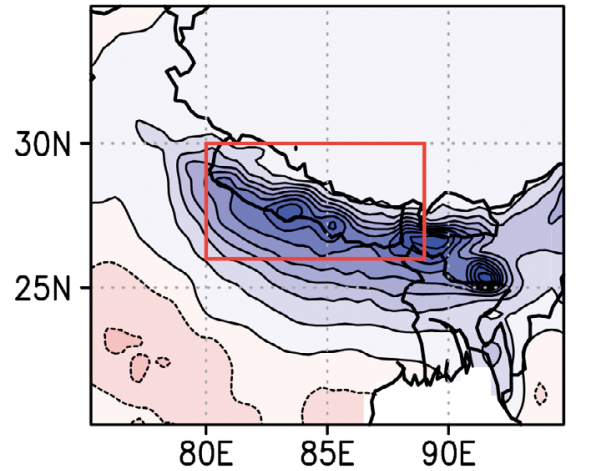

(c) Break (1971-2000)

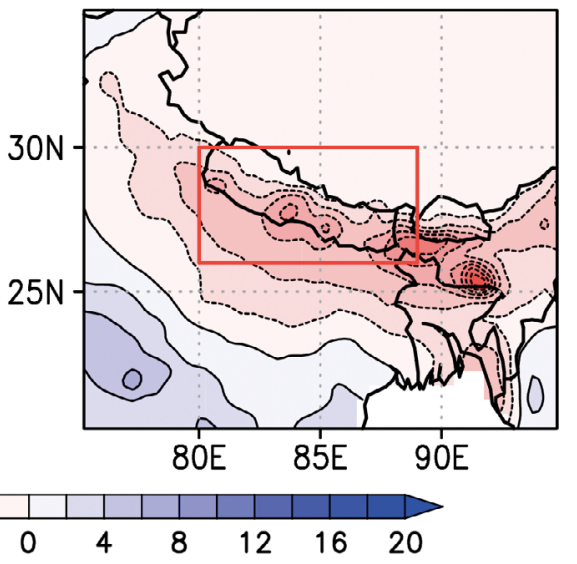

Precipitation anomaly $\left(\mathrm{mm} \mathrm{d}^{-1}\right)$

Fig. 3. (a) 9 to 90 d filtered precipitation anomaly (solid line in upper panel) and daily rainfall averaged over part of the the central Himalayan region $\left(26^{\circ}\right.$ to $30^{\circ} \mathrm{N}, 80^{\circ}$ to $89^{\circ} \mathrm{E}$ ) (bars in lower panel) from 1 June to 30 September 1981. Dashed lines in the upper panel denote the climatological mean \pm 1 SD of daily rainfall during 1971-2000. The blue (red) line with dots in the upper panel shows active (break) spells. The solid line in the lower panel shows the climatological mean of the first 3 harmonics. (b) Composites of active and (c) break spells of monsoons. The red rectangles in (b) and (c) indicate the area used to create the daily precipitation index

sonable spatial patterns of seasonal climatology (ACCESS1.0, CNRM-CM5, EC-EARTH, GFDL-ESM2G, GFDL-ESM2M, HadGEM2-AO, HadGEM2-CC, Had GEM2-ES, INMCM4, and IPSL-CM5A-LR) (Fig. 4b). Similarly, only 8 models performed well in simulating the spatial pattern of IAV (ACCESS1.0, ACCESS1.3, CMCC-CMS, CNRM-CM5, EC-EARTH, HadGEM2AO, HadGEM2-CC, and HadGEM2-ES) (Fig. 4c). An inability of GCMs to represent IAV is evident (Sharmila et al. 2015, Alves et al. 2016).
Taylor diagrams revealed that none of the models performed equally well in simulations of the 3 metrics used for this study. For example, BCC-CSM1.1m is one of the best models for reproducing the annual cycle, but its performance is much poorer when reproducing the spatial pattern of climatology and IAV. Similarly, INMCM4 is reliable for simulating the annual cycle and spatial patterns of seasonal mean precipitation, but it failed to simulate the spatial pattern of IAV. The CCs of MIROC5 are almost 


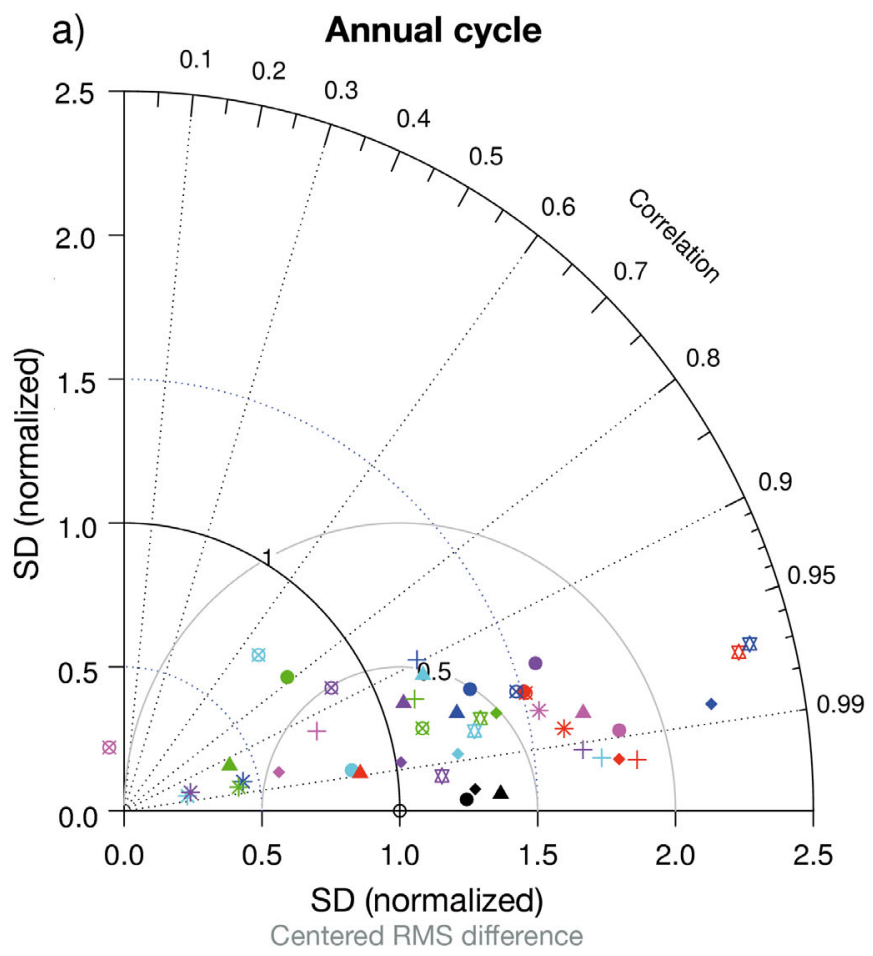

C) Spatial pattern of JJAS Interannual Variability

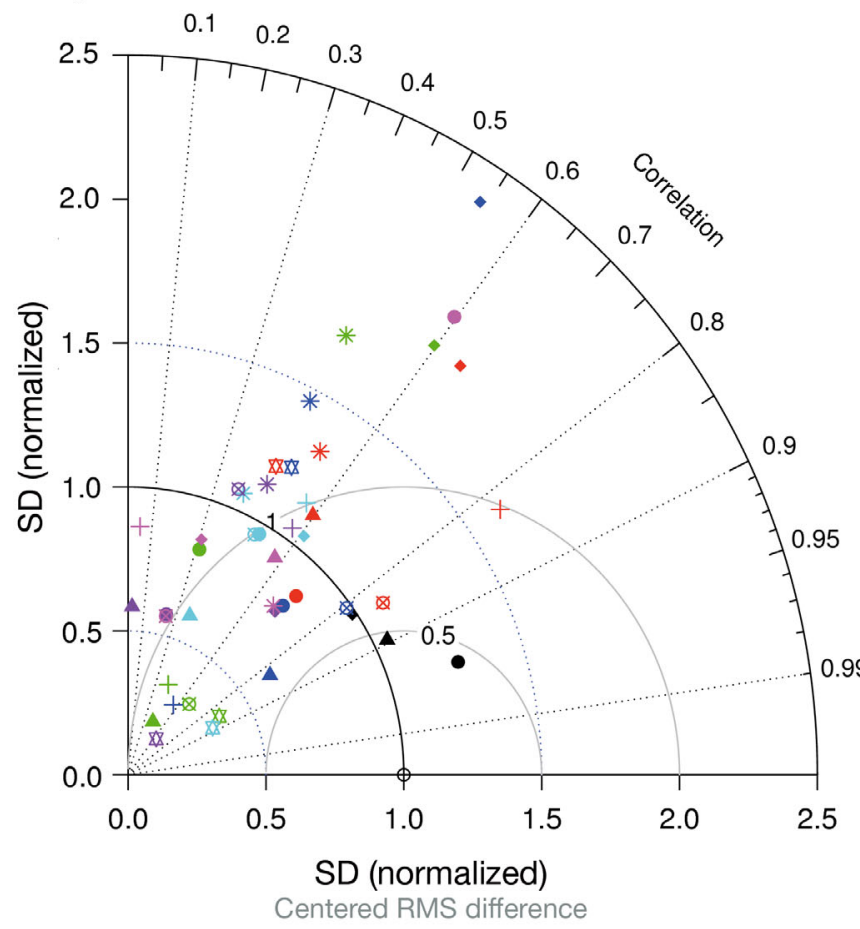

\section{b) Spatial pattern of JJAS precipitation}

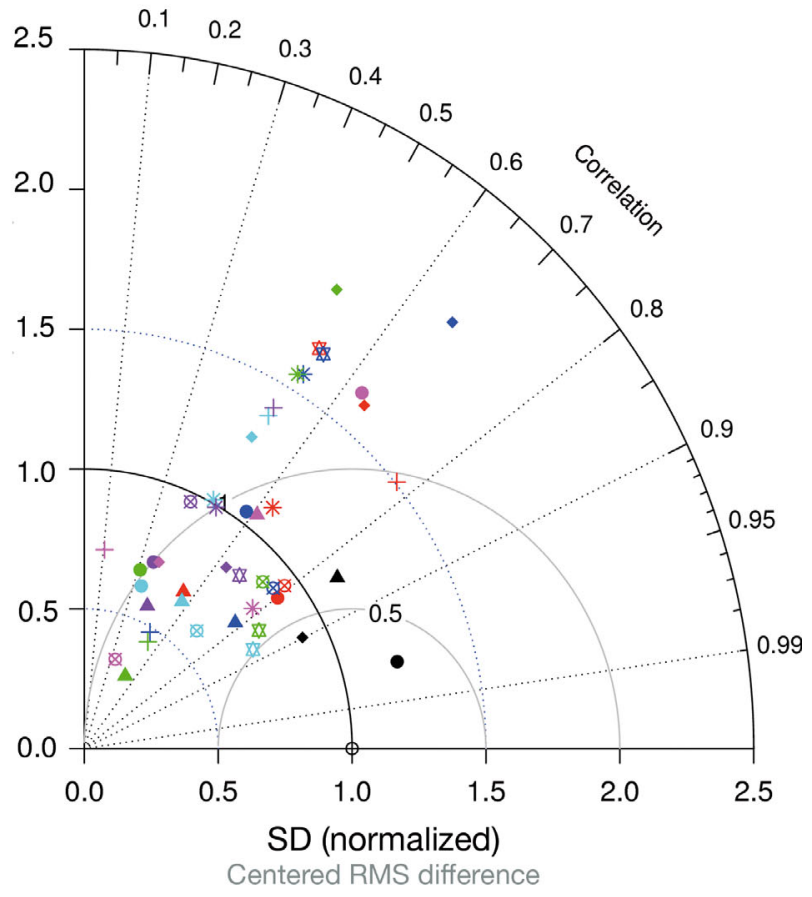

O APHRODITE

CRC

- GPCC

ACCESS 1.0

BCC-CSM1.1

BCC-CSM1.1

BNU-ESM

CESM1-BGC

CESM1-CAM

CMCC-CMS CMCC-CMS
CNRM-CM5 CSTRO-Mk3.6.0 CanESM2

EC EARTH

FGOALS-g2
FIO-ESM

GFDL-CM3

GFDL-ESM2G

* GFDL-ESM2M

䊅 GISS-E2-H-CC

GISS-E2-R
GISS-E2-R-CC

HadGEM2-AO

HadGEM2-CC

HadGEM2-
INMCM4

IPSL-CM5A-LR

$\otimes$ IPSL-CM5A-MR

IPSL-CM5B-LR
+ MIROC5

MIROC-ESM

- MPI-ESM-LR

MRI-CGCM3

NorESM1-M

NorESM
MMM3

MMM4

MMM38 Himalayan region (CHR), (b) spatial pattern of climatological summer monsoon season (SMS) mean precipitation, and (c) spatial pattern of interannual variability measured by the standard deviation (SD) of SMS mean precipitation during 1971-2000. Data are shown relative to the APHRODITE observation dataset for 3 additional observation datasets (CPC, CRU, GPCC; solid black symbols), 38 model means (MMMs). Distance from the center of $X$-axis, identified as reference (APHRODITE), shows centered root mean square difference, and azimuthal angle shows Pearson correlation coefficient between APHRODITE and other observed and model datasets CMIP5 model projections and 3 multi- identical to observation datasets $(\mathrm{CPCC}, \mathrm{CPC}$ and CRU) in simulations of all 3 metrics, but it has extremely large NSD compared to reference data. In general, the models that are reliable for representing spatial patterns are reliable for representing the annual cycle.
With the background of model capabilities explained above, 6 models are identified as the best performing models based on the criteria defined in Section 2.4.1: ACCESS1.0, CNRM-CM5, EC-EARTH, HadGEM2-AO, HadGEM2-CC, and HadGEM2-ES. Among these, the 3 HadGEM2 models, run with the 
Table 3. Climatological mean bias of precipitation averaged over the central Himalayan region (CHR) for the summer monsoon season (SMS, June-September) during the present period (1971-2000). Data are shown for 3 additional observation datasets (CPC, CRU, GPCC), 38 CMIP5 model projections and multi-model means. Bias is calculated related to APHRODITE SMS mean precipitation $\left(5.13 \mathrm{~mm} \mathrm{~d}^{-1}\right)$. Intermodel standard deviation: $2.85 \mathrm{~mm} \mathrm{~d}^{-1}$; inter-model range: $10.09 \mathrm{~mm} \mathrm{~d}^{-1}$

\begin{tabular}{|c|c|c|c|}
\hline Dataset & $\begin{array}{c}\text { Bias } \\
\left(\mathrm{mm} \mathrm{d}^{-1}\right)\end{array}$ & Dataset & $\begin{array}{c}\text { Bias } \\
\left(\mathrm{mm} \mathrm{d}^{-1}\right)\end{array}$ \\
\hline APHRODITE & - & GISS-E2-H & -2.50 \\
\hline $\mathrm{CPC}$ & 2.01 & GISS-E2-H-CC & -2.53 \\
\hline CRU & 1.56 & GISS-E2-R & -3.48 \\
\hline GPCC & 1.36 & GISS-E2-R-CC & -3.43 \\
\hline ACCESS1.0 & 2.75 & HadGEM2-AO & 2.93 \\
\hline ACCESS1.3 & 1.92 & HadGEM2-CC & 2.89 \\
\hline BCC-CSM1.1 & -0.96 & HadGEM2-ES & 2.61 \\
\hline BCC-CSM1.1m & 0.13 & INMCM4 & 1.20 \\
\hline BNU-ESM & 3.32 & IPSL-CM5A-LR & -1.63 \\
\hline CCSM4 & 4.74 & IPSL-CM5A-MR & -0.57 \\
\hline CESM1-BGC & 4.62 & IPSL-CM5B-LR & -3.39 \\
\hline CESM1-CAM5 & 6.02 & MIROC5 & 4.92 \\
\hline $\mathrm{CMCC}-\mathrm{CM}$ & 2.07 & MIROC-ESM & 2.53 \\
\hline CMCC-CMS & 2.01 & MIROC-ESM-CHEM & 2.43 \\
\hline CNRM-CM5 & 0.60 & MPI-ESM-LR & 4.06 \\
\hline CSIRO-Mk3.6.0 & -2.11 & MPI-ESM-MR & 3.61 \\
\hline CanESM2 & -0.46 & MRI-CGCM3 & -1.41 \\
\hline EC-EARTH & 1.66 & NorESM1-M & 6.49 \\
\hline FGOALS-g2 & -1.92 & Nor-ESM-ME & 6.61 \\
\hline FIO-ESM & 1.42 & MMM3 & 1.99 \\
\hline GFDL-CM3 & 1.09 & MMM4 & 1.91 \\
\hline GFDL-ESM2G & 3.47 & MMM38 & 1.45 \\
\hline GFDL-ESM2M & 3.52 & & \\
\hline
\end{tabular}

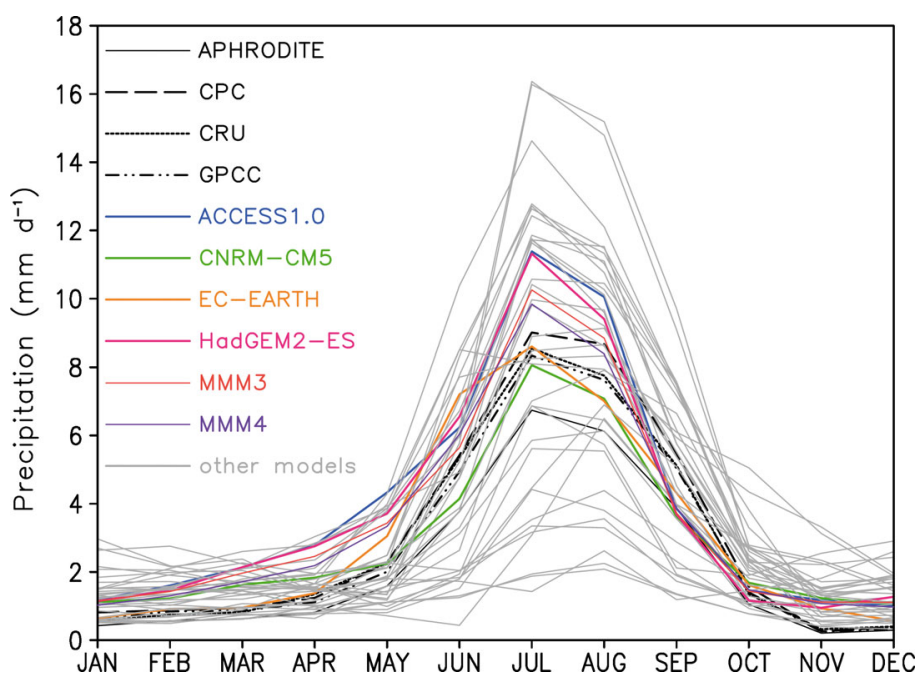

Fig. 5. Annual cycle of precipitation over the central Himalayan region (CHR) from 4 observational datasets (black lines), simulations of 4 selected CMIP5 best models and their multi-model means (coloured lines), and simulations of 34 other CMIP5 models (grey lines) for the period 1971-2000 same horizontal resolutions but with different complexities in terms of the inclusion of complex physical processes (The HadGEM2 Development Team 2011), show almost identical skills to reproduce present climatology (Fig. 4a-c). Consequently, only HadGEM2ES is considered for additional study because it is better than the other 2 HadGEM2 models. Therefore, the 4 best models namely ACCESS1.0, CNRM-CM5, EC-EARTH and HadGEM2-ES and their MMM (i.e. MMM4) are used to study the future evolution of precipitation under RCP4.5 and RCP8.5 scenarios. However, RCP4.5 scenario datasets of EC-EARTH were not accessible at the time of analysis. Therefore, we also constructed a MMM of the 3 best models (MMM3) excluding EC-EARTH. MMMs show better capability for reproducing the annual cycle (Fig. 4a) and spatial distribution of SMS mean precipitation climatology (Fig. 4b). However, MMMs are unreliable for spatial patterns of IAV (Fig. 4c). Among MMMs, MMM38 is the best for the annual cycle but the poorest for the spatial pattern of seasonal mean and IAV because of the inclusion of unreliable models.

We also computed the area averaged mean of SMS mean precipitation over the CHR during the present climate, and then analyzed its inter-model spread, range and bias (Table 3). The reference dataset, APHRODITE, shows mean precipitation of $5.13 \mathrm{~mm}$ $\mathrm{d}^{-1}$ for 1971-2000. The inter-model range is as large as two times $\left(10.09 \mathrm{~mm} \mathrm{~d}^{-1}\right)$ the reference dataset value, whereas the inter-model spread is $55 \%$ of the reference dataset value. Two-thirds of the total models and other observation datasets show a wet bias. Biases of MMMs are almost identical to the biases of observation datasets.

For more detail, the annual cycle of the best models and their MMMs is presented in Fig. 5. A large intermodel spread is evident in the shape and size of the annual cycle. The model uncertainty is large during the monsson season. It is noteworthy that APHRODITE precipitation is lower than those of other observation datasets as well as the best models, particularly during the monsoon season. The spatial distribution of SMS precipitation and its IAV are presented respectively in Figs. 6 \& 7. The spatial patterns of large-scale mean precipitation and IAV among the observations show remarkable consistency. The best models show reliable skill in simulating spatial patterns of seasonal mean climatology (Fig. 6) and, to some extent, IAV (Fig. 7). However, local biases exist in many regions. ACCESS1.0 and HadGEM2-ES simulations show similar patterns of climatology and bias as they are based on atmospheric components from 

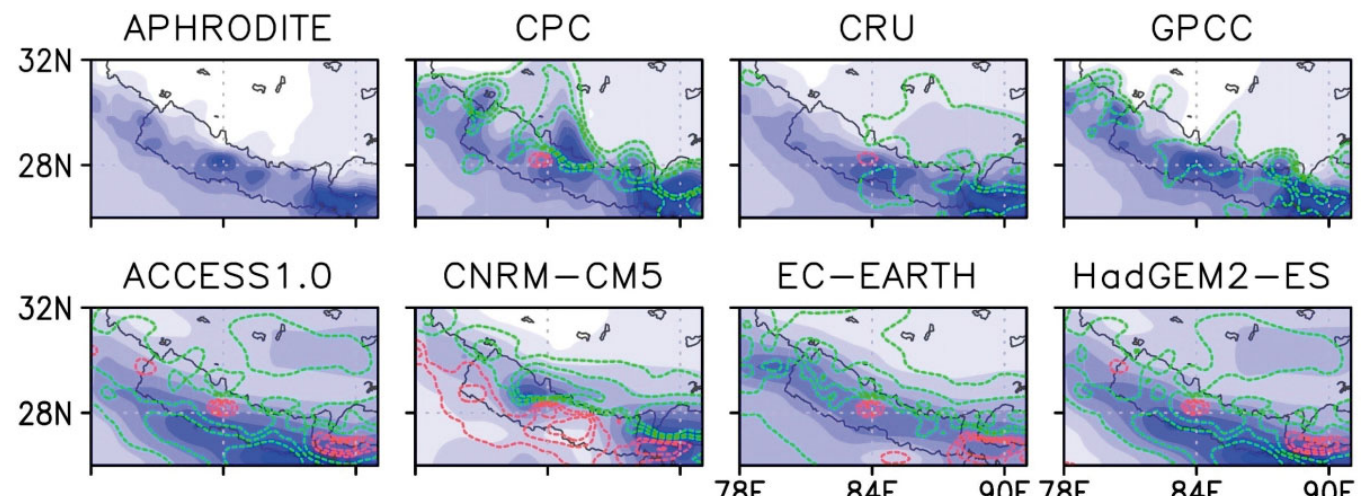

HadGEM2-ES
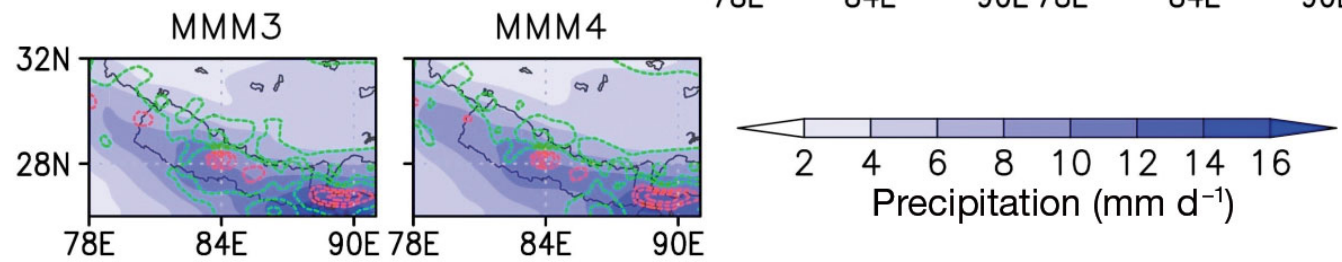

Fig. 6. Mean precipitation climatology (blue shading) and bias (contours) with respect to the APHRODITE observation dataset (top left) for the SMS (June-September) season during 1971-2000. Comparative data are shown for 3 additional observation datasets (CPC, CRU and GPCC; upper row), 4 selected best CMIP5 models and the multi-model means of 3 (MMM3) and 4 (MMM4) best models. Dry bias is indicated by red contours $\left(-2,-4\right.$ and $\left.-6 \mathrm{~mm} \mathrm{~d}^{-1}\right)$ and wet bias is indicated by green contours $\left(2,4\right.$ and $\left.6 \mathrm{~mm} \mathrm{~d}^{-1}\right)$
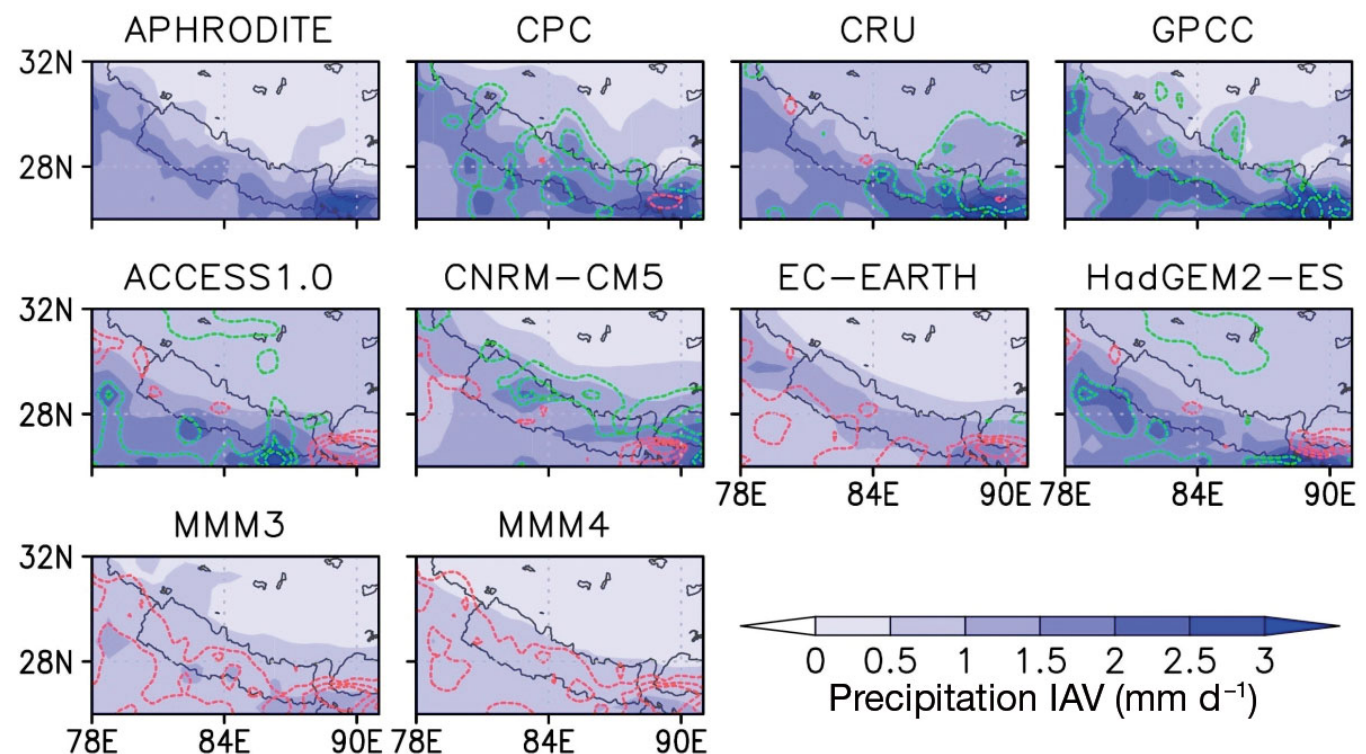

MMM4
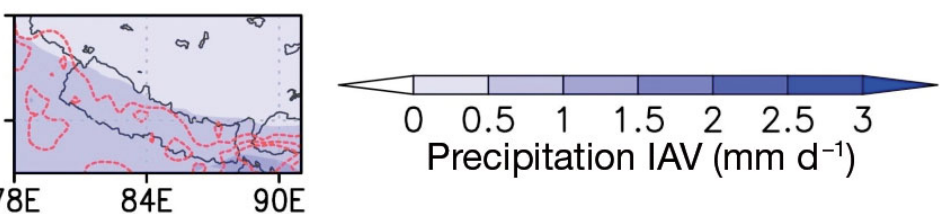

Fig. 7. Interannual variability (IAV) of SMS mean precipitation (blue shading) and bias in IAV (contours) with respect to APHRODITE during 1971-2000. Comparative data are shown for 3 additional observation datasets (CPC, CRU and GPCC; upper row), 4 selected best CMIP5 models and their multi-model means (MMMs). Dry bias is indicated by red contours ( -1.5 , -1 and $\left.-0.5 \mathrm{~mm} \mathrm{~d}^{-1}\right)$ and wet bias is indicated by green contours $\left(0.5,1.0\right.$ and $\left.1.5 \mathrm{~mm} \mathrm{~d}^{-1}\right)$

the same model family (Bi et al. 2013, Knutti et al. 2013). CNRM-CM5 has a noticeable dry bias (Fig. 6) and lower IAV over southeastern parts (Fig. 7). The MMMs of best models show reasonable skill in assessing mean precipitation (Fig. 6), but smooth out the IAV (Fig. 7) (Sperber et al. 2013). Because IAV of MMMs is not reliable, further analysis of IAV is not performed based on MMM data.

\subsection{Projected change in future warming scenarios}

\subsubsection{Changes in SMS precipitation climatology}

The annual cycles of daily precipitation (smoothed by removing the first 3 harmonics) of the best models and their multi-model means for the near-, mid- and far-future periods under RCP4.5 and RCP8.5 scenar- 

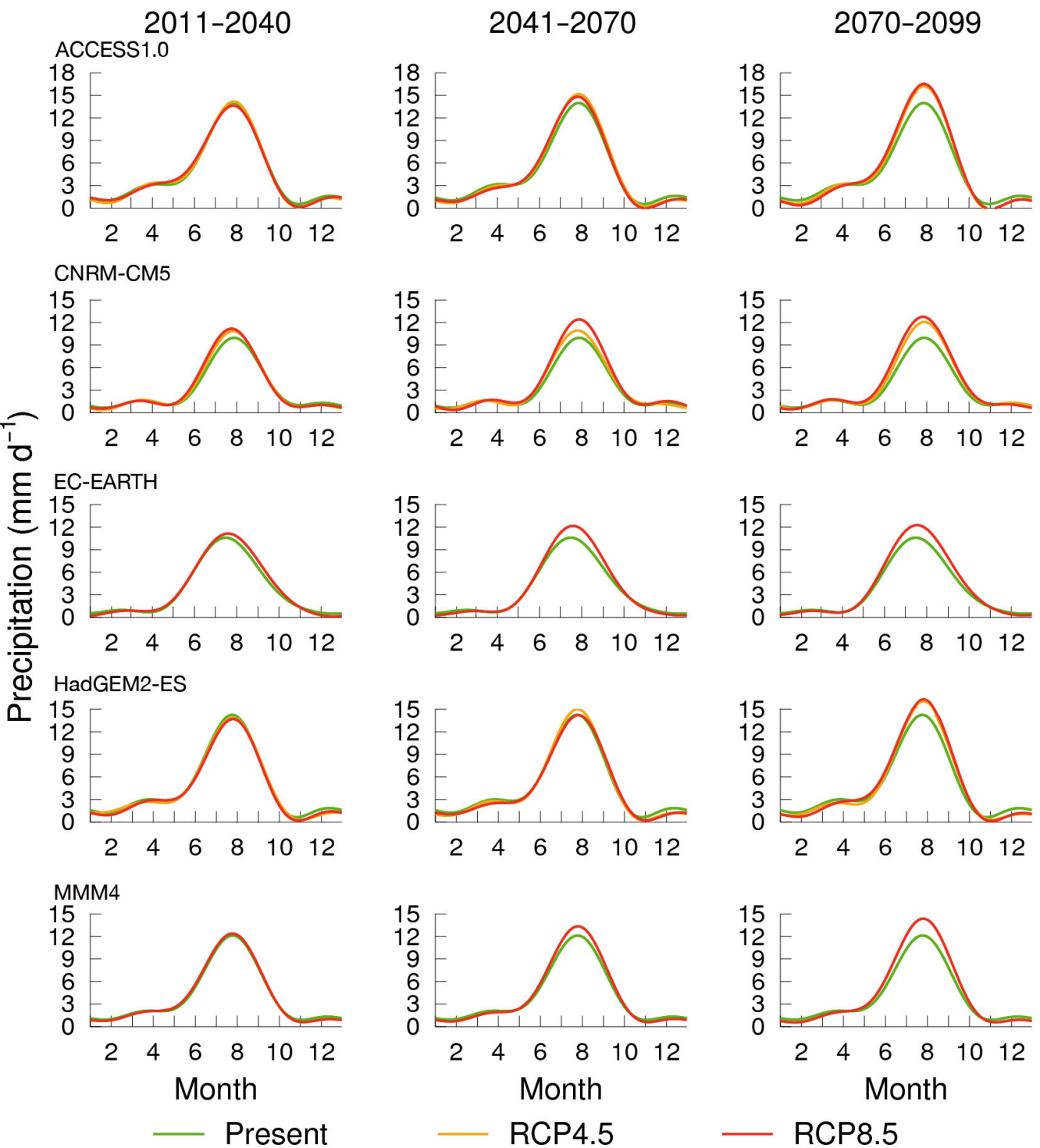

Fig. 8. Annual precipitation cycle in the central Himalayan region (CHR) based on simulations by the 4 best CMIP5 models and the multi-model means of 4 (MMM4) best models for the present climate (green), and for near-future (2011-2040; left panels), mid-future (2041-2070; centre panels) and far-future (2070-2099; right panels) periods under RCP4.5 (pale orange) and RCP8.5 (dark orange) scenarios. The annual cycle is constructed from the climatological mean of the first 3 harmonics to facilitate a visual comparison of the phase and amplitude

ios with their corresponding annual cycle at the present condition are depicted in Fig. 8. Except HadGEM2-ES for near- and mid-future periods, all models projected an increase in the amplitude of precipitation during the summer monsoon (June-September) in all future time slices under both warming scenarios. However, no large difference exists in the amplitudes of precipitation projection between RCP4.5 and RCP8.5. The amplitude increases gradually from the near-future to far-future periods. The increase is large in July and August, with a value of about $3 \mathrm{~mm} \mathrm{~d}^{-1}$ in the far-future period. Winter pre- cipitation (December-February) is projected to decrease slightly by multi-model means and member models (Fig. 8).

Table 4 presents the change in area-averaged SMS mean precipitation over CHR and its IAV for near-, mid-, and far-future periods under both warming scenarios relative to the present climatology. The areaaveraged precipitation is projected to increase gradually from near- to far-future periods. It is highest for the far-future period under RCP8.5. Models consistently project increased precipitation in the mid- and far-future periods under both warming scenarios with 
Table 4. Changes in mean and interannual variability (IAV) of SMS (June-September) precipitation projected by 4 selected best CMIP5 models and their multi-model means (MMMs), averaged over the central Himalayan region (CHR) for near-future (2011-2040), mid-future (2041-2070) and far-future (2070-2099) periods. MMM4 is the MMM of the 4 selected models. RCP4.5 scenario datasets of EC-EARTH were not accessible at the time of analysis. Therefore, we also constructed a MMM of the 3 best models (MMM3) excluding EC-EARTH. Confidence levels $\left({ }^{* *} 99 \%\right.$; $\left.{ }^{*} 95 \%\right)$ of mean and interannual variation change were calculated, respectively, using Student's $t$-test and Levene's test

\begin{tabular}{|c|c|c|c|c|c|c|}
\hline \multirow[t]{2}{*}{ Model } & \multicolumn{2}{|c|}{ 2011-2040 } & \multicolumn{2}{|c|}{ 2041-2070 } & \multicolumn{2}{|c|}{ 2070-2099 } \\
\hline & $\mathrm{RCP} 4.5$ & RCP8.5 & $\mathrm{RCP} 4.5$ & RCP8.5 & $\mathrm{RCP} 4.5$ & RCP8.5 \\
\hline \multicolumn{7}{|c|}{ Change in seasonal mean precipitation (\%) } \\
\hline ACCESS1.0 & 2.16 & -0.83 & $9.38^{* *}$ & $6.33^{* *}$ & $12.67^{* *}$ & $17.39^{* *}$ \\
\hline CNRM-CM5 & 8.24 & $10.72^{* *}$ & $9.84^{* *}$ & $20.28^{* *}$ & $17.71^{* *}$ & $27.55^{* *}$ \\
\hline EC-EARTH & - & $7.34^{* *}$ & - & $12.91^{* *}$ & - & $15.45^{* *}$ \\
\hline HadGEM2-ES & 4.83 & 2.27 & $9.94^{* *}$ & $7.68^{* *}$ & $17.85^{* *}$ & $20.58^{* *}$ \\
\hline MMM3 & $4.76^{*}$ & 3.39 & $9.71^{* *}$ & $10.56^{* *}$ & $15.90^{* *}$ & $21.27^{* *}$ \\
\hline MMM4 & - & $4.35^{*}$ & - & $11.13^{* *}$ & - & $19.87^{* *}$ \\
\hline \multicolumn{7}{|c|}{ Change in IAV of seasonal mean precipitation (\%) } \\
\hline ACCESS1.0 & -21.18 & -12.20 & 17.72 & -6.32 & -1.69 & 36.28 \\
\hline CNRM-CM5 & $73.68^{*}$ & 44.84 & 19.61 & 35.77 & 48.10 & $63.72^{* *}$ \\
\hline EC-EARTH & - & 7.71 & - & $58.34^{*}$ & - & $55.71^{* *}$ \\
\hline HadGEM2-ES & -12.61 & -3.27 & -1.84 & 15.06 & -8.05 & 15.63 \\
\hline
\end{tabular}

a $99 \%$ confidence level. However, projections are inconsistent for the near-future period. The projected change in mean precipitation is about -1 to $27 \%$. MMMs projected an increase of about $20 \%$ of mean precipitation at the $99 \%$ confidence level.

In contrast to mean precipitation, models project mixed tendencies for changes in the IAV of SMS mean precipitation in all future time periods under both warming scenarios, except for far-future periods under the RCP8.5 scenario. Some models show a significantly increasing tendency, while others show a decreasing tendency for the same periods under the same scenario (Table 4). However, models are consistent in revealing increasing variation during the far-future period under RCP8.5. Increased variation indicates irregular SMS precipitation, which strongly affects decision making in every sector from agriculture to water resource management. It is noteworthy that future projections of IAV are inconsistent. This result suggests that projection data must be considered carefully when used to study climate change impacts.

Fig. 9 presents relative changes in the spatial pattern of SMS mean precipitation climatology for the far-future period under the RCP8.5 scenario. Precipitation is projected to increase considerably over most parts of the CHR by all the best models and MMMs. However, regional uncertainty exists. Most models project slight and not significant decreasing tendencies over northwestern parts of the study area.
ACCESS1.0 and HadGEM2-ES project similar spatial patterns of SMS mean precipitation climatology change, which possibly derives from their use of common atmospheric models (Bi et al. 2013, Knutti et al. 2013).

Projection of possible IAV change of SMS mean precipitation during the far-future period under RCP8.5 is presented in Fig. 10. The model consensus on changes in IAV spatial pattern is low, indicating considerable uncertainty. However, most of the best models consistently reveal increasing IAV over Nepal with some models showing statistically significant increasing IAV.

Projected changes in mean precipitation and IAV are robust in the far-future period under the RCP8.5 scenario. Therefore, further analysis specifically addresses the projected changes only in the far-future period under the RCP8.5 scenario.

\subsubsection{Changes in extreme indices}

Changes in daily precipitation characteristics. Changes in the frequency and intensity of extreme events are well known to have stronger effects on the socioeconomy than seasonal mean changes. Mishra et al. (2014) concluded that the ensemble mean of best GCMs performed better than RCMs for simulating indices of extreme events over India. Wet extremes and daily intensity are projected to increase and rainy days are projected to decrease over the Himalayas in future warming scenarios (Palazzi et al. 2013). It is therefore worthwhile to analyze the changes in frequency of daily precipitation projected by the best GCMs and their MMM for the central Himalayas.

Fig. 11 portrays projected changes in frequency distribution of daily precipitation under the RCP8.5 scenario during SMS in the far-future period. A MMM of daily precipitation simulated by the 4 best models (MMM4) is created by assigning equal weight to each model, as with MMM4 of monthly precipitation. HadGEM2-ES has $360 \mathrm{~d}$ in $1 \mathrm{yr}$, $120 \mathrm{~d}$ in SMS and $30 \mathrm{~d}$ in each month. Consequently, MMM4 also has $120 \mathrm{~d}$ in SMS. To enable 

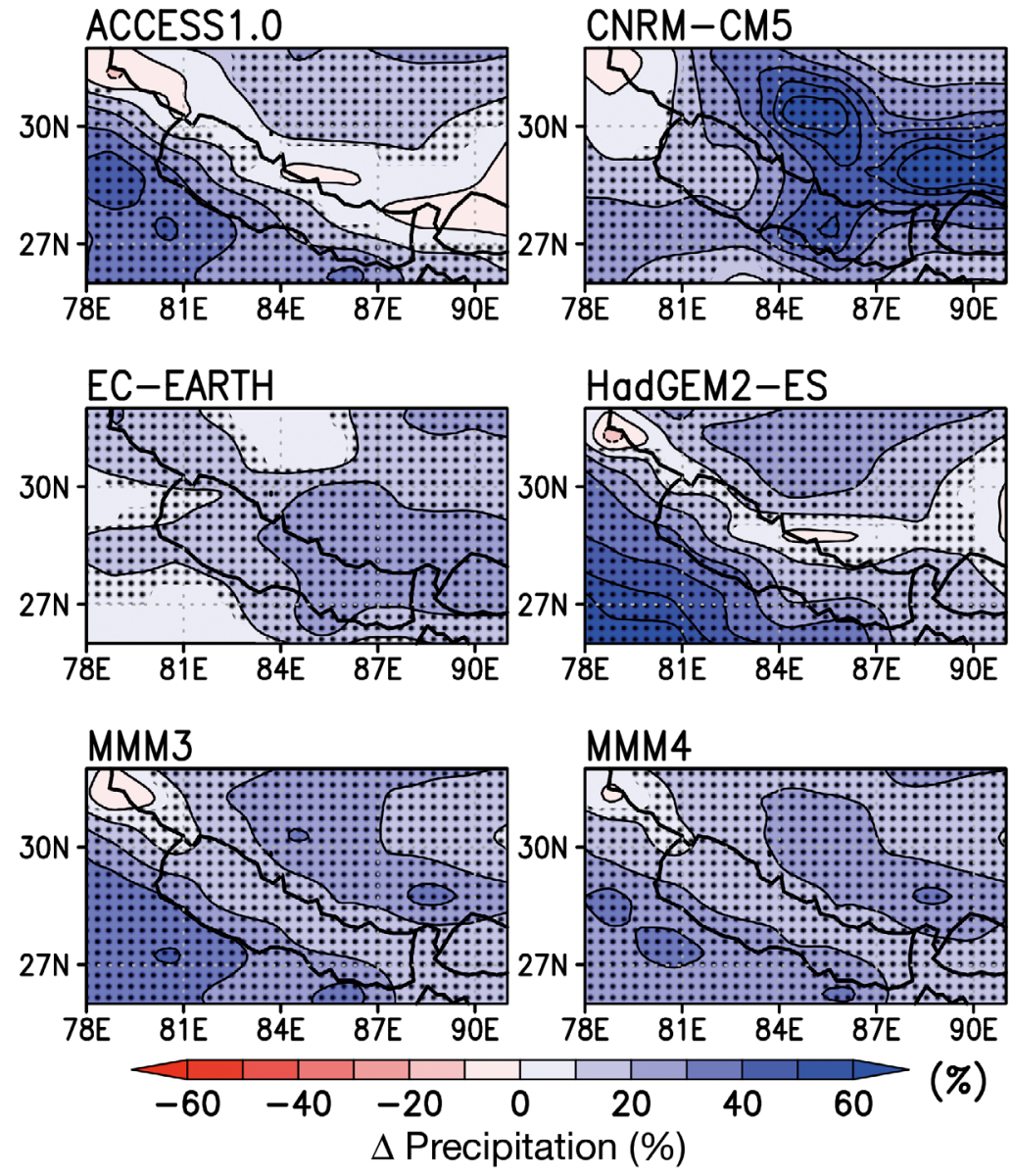

Fig. 9. Spatial distribution of projected change in SMS precipitation in the central Himalayan region (CHR) during 2070-2099 under RCP8.5 relative to the present (1971-2000) climatology. Data are shown for 4 selected best CMIP5 models and their multi-model means of 3 (MMM3) and 4 (MMM4) best models. Stippled areas are significant at the $95 \%$ confidence level. The level of significance was assessed using Student's $t$-test for equal and unequal variances based on Levene's test
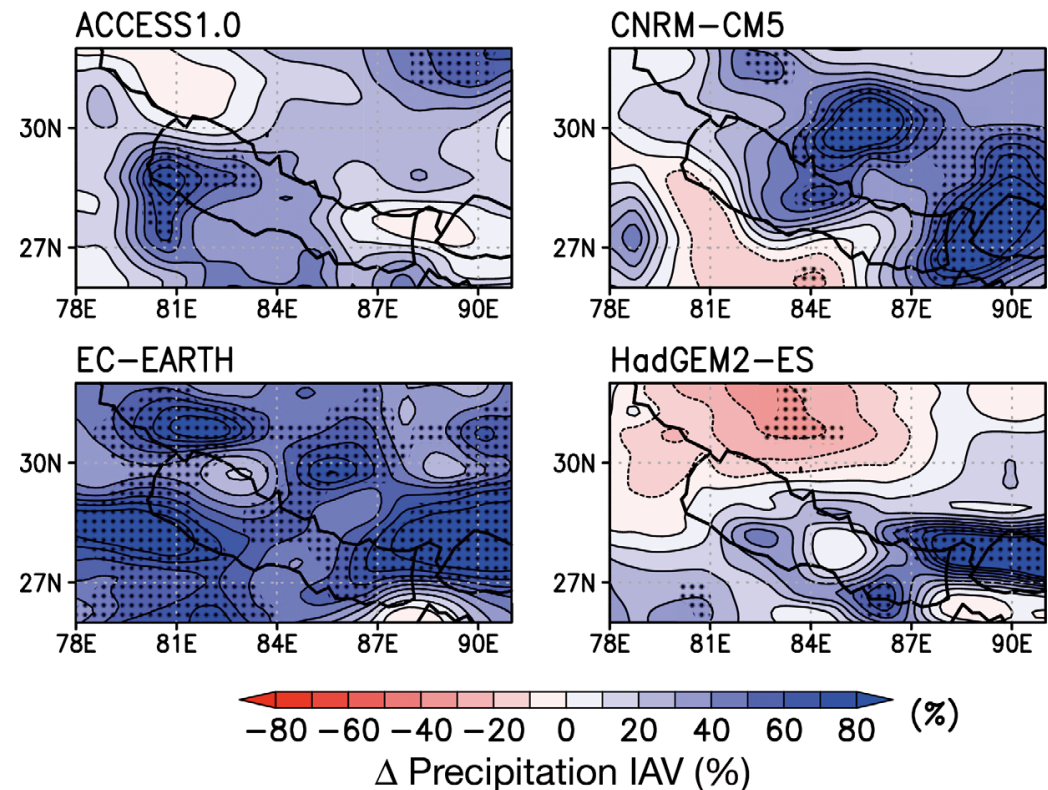

comparative analysis, calculated frequencies of HadGEM2-ES and MMM4 are adjusted to 122 days, multiplying by a scaling factor (122/ 120). The 4 best models and MMM4 consistently project a decrease in light precipitation days over most parts of the study area. However, ACCESS1.0 and HadGEM2-ES show an increase in light rain-rate events over Nepal. These 2 models have quite similar response for all rain-rates. Moderate and heavy precipitation days are projected to increase. However, model convergence in spatial patterns of projected changes in the frequency of moderate precipitation over Nepal is low. ACCESS1.0 and HadGEM2-ES show decreased frequencies of moderate precipitation over Nepal. The decrease in light to moderate rainfall over the Himalayan foothills and Nepal might be attributable to the shift from light to moderate rainfall to heavy rainfall categories under warming scenarios. The projected increase in moderate and heavy precipitation days is expected to be accompanied by a possible increase in precipitation-induced hazards such as floods and landslides.

Changes in active and break spells. Active and break spells of monsoon are known to affect the monsoon season total precipitation (Rajeevan et al. 2010) and IAV of SMS mean precipitations (Krishnamurthy \& Shukla 2000). Break spells of long duration are known to have a strong effect on raindependent agricultural production (Gadgil \& Joseph 2003). Therefore, active and break spells of monsoons

Fig. 10. Spatial distribution of projected change in interannual variability (IAV) of SMS precipitation in the central Himalayan region (CHR) during 2070-2099 under RCP8.5 relative to the present (1971-2000) climatology. Data are shown for 4 selected best CMIP5 models; MMM3 and MMM4 are not shown here because these MMMs are not reliable to simulate IAV for the present climate. The level of significance in this case was tested using Levene's test 


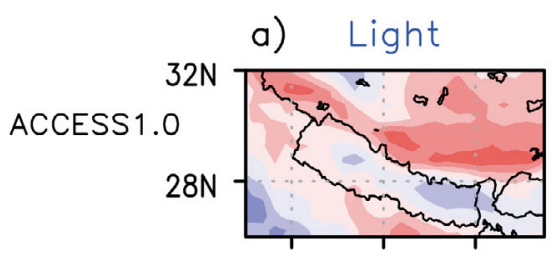

b)

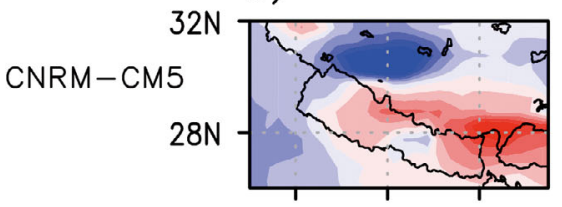

c)

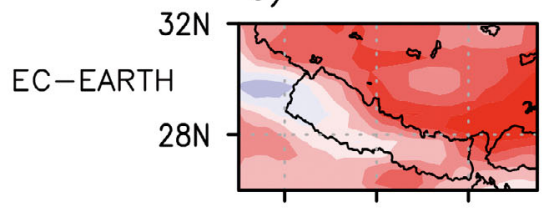

d)

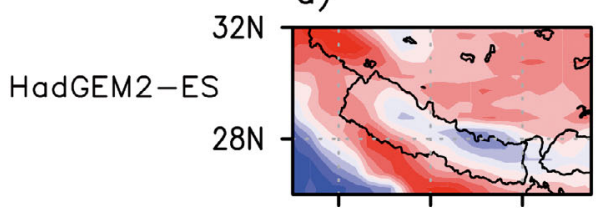

e)

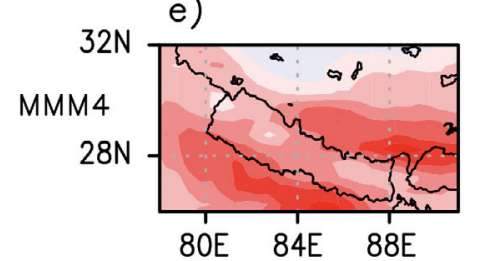

$80 \mathrm{E} \quad 84 \mathrm{E} \quad 88 \mathrm{E}$ f) Moderate

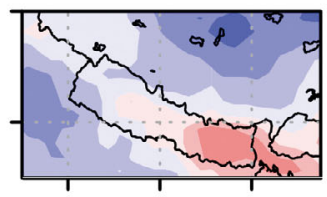

g)

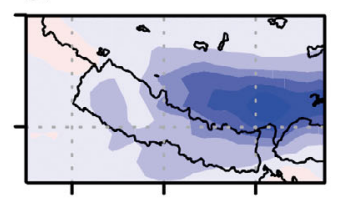

h)

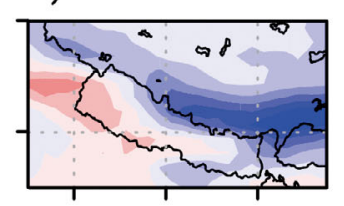

i)

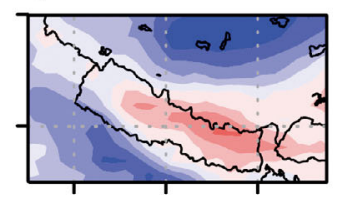

j)

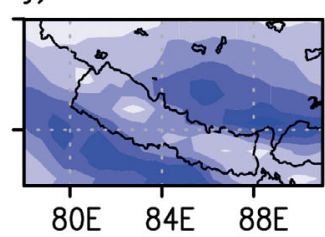

k) Heavy

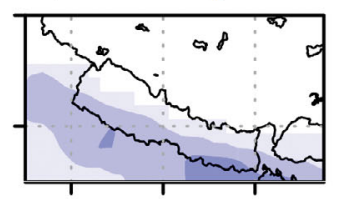

1)

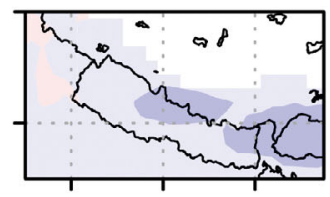

m)

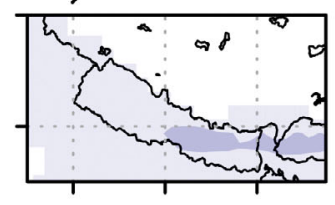

n)

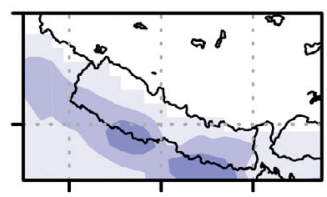

o)

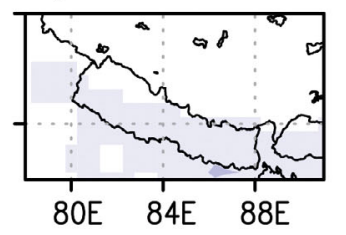

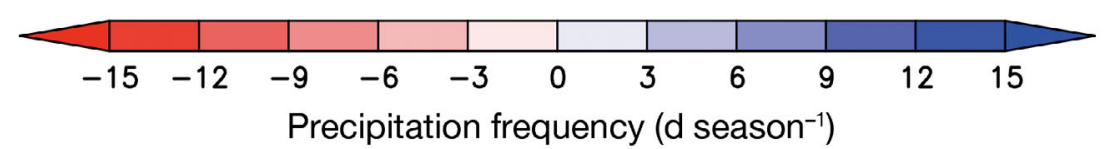

Fig. 11. Projected changes in the frequency $\left(\mathrm{d}_{\mathrm{season}}{ }^{-1}\right)$ distribution of daily SMS precipitation (light: $1-10 \mathrm{~mm} \mathrm{~d}^{-1}$; moderate: 10-40 $\mathrm{mm} \mathrm{d}^{-1}$; heavy: >40 $\mathrm{mm} \mathrm{d}^{-1}$ ) under RCP8.5 during 2070-2099. Data are shown for 4 selected best CMIP5 models and their multi-model mean (MMM4)

simulated by models for both the present and future under the RCP8.5 warming scenario are analyzed in this study. Best models and MMM4 perform reasonably well when simulating the frequency and length of active and break spells under the present climate (Fig. 12). However, the spread in the length of break spells is greater than in the length of active spells in the present climatology (Fig. 12b,d). Best models and MMM4 consistently project a gradual increase in the frequency and length of active and break spells. However, inter-model spread is larger for break spells than active spells.

\section{DISCUSSION}

A key obstacle hindering evaluation of model simulation over the Himalayas is the lack of a reliable observation dataset (Yatagai et al. 2012, Palazzi et al. 2013, Mishra 2015). Available gridded observed precipitation datasets show discrepancies (Figs. 4-7, Table 3) indicating uncertainty in observation datasets, which complicates model evaluation (Ramesh \& Goswami 2014). We used the APHRODITE precipitation dataset as a reference because this dataset is good for the Himalayan region (Andermann et al. 


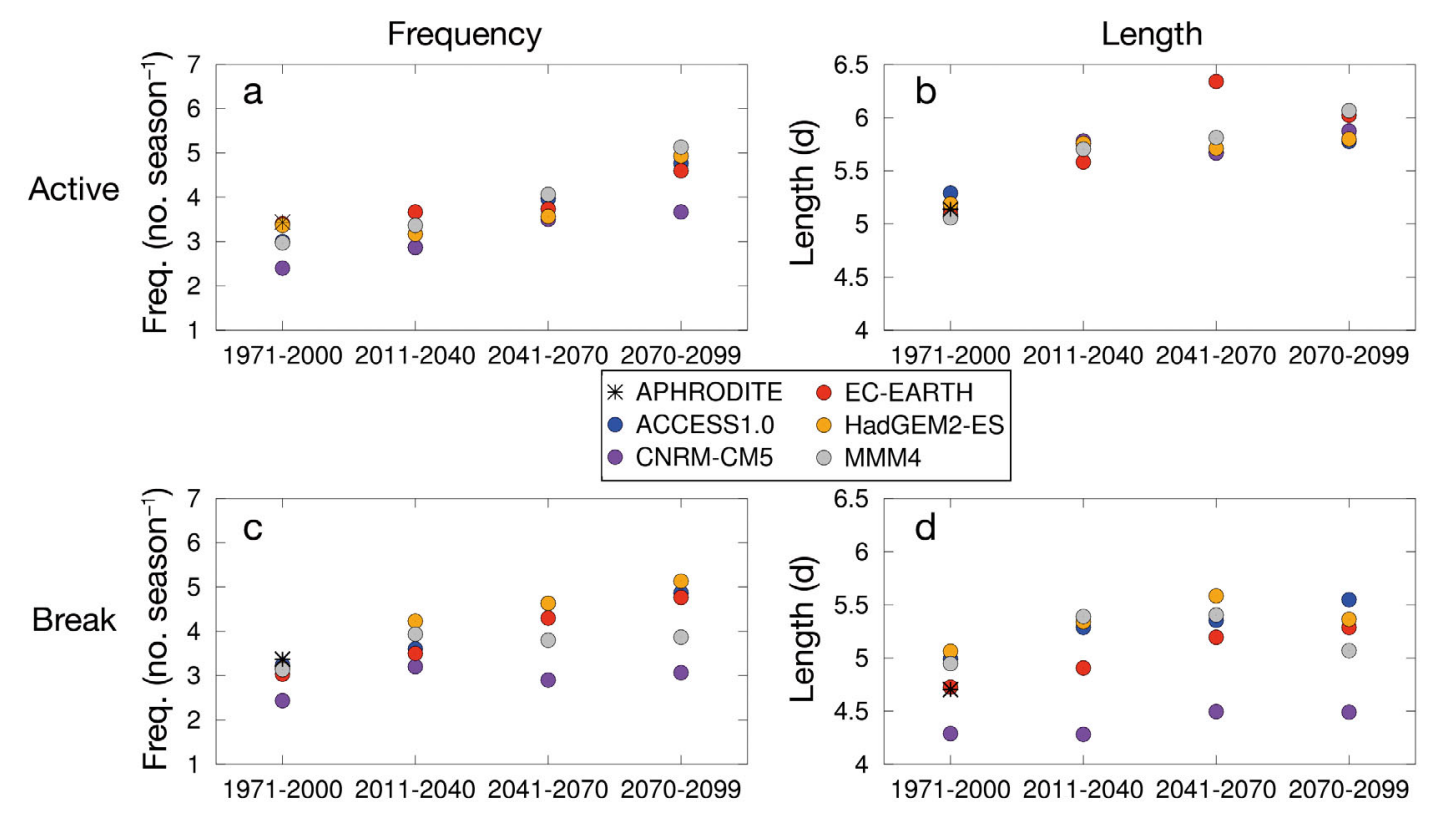

Fig. 12. (a) Frequency and (b) length of active spells and (c) frequency and (d) length of break spells during SMS in the central Himalayan region (CHR). Data for the present period (1971-2000) are shown for the APHRODITE observation dataset, and simulated data for present period and future period under RCP8.5 is shown for 4 selected best CMIP5 models and their multi-model mean (MMM4)

2011, Yatagai et al. 2012, Tong et al. 2014, Prakash et al. 2015). However, the sparse observation network over the Tibetan plateau and the high Himalayas might lead to underestimation of precipitation over the region (Yatagai et al. 2012). A second issue, not considered here, is the problem of mapping coarse resolution values from the models to the slightly fine resolution of APHRODITE, which would likely result in lower predictive capability (McBride \& Ebert 2000). Consequently, enhancement of the observation network is recommended to provide a representative precipitation dataset for the Himalayan region.

The complex topography of the Himalayas plays a vital role in changing local wind circulation and precipitation characteristics. Spatial and temporal variability of precipitation are intertwined, with local drivers such as topography and land use interacting with remotely connected variables such as ENSO (Shrestha 2000, Shrestha et al. 2000). Consequently, reliable representation of topography and physical processes in climate models is important for the realistic simulation of regional precipitation (Fennessy et al. 1994, Turner \& Annamalai 2012, Rajendran et al. 2013). State-of-the-art GCMs differ from each other in many ways, including in their formulations, inclusion of different coupled components such as carbon cycles and stratospheric processes, parameterization of different physical processes, and model resolutions. These differences are reflected in their simula- tions (Fig. 4, Table 3). However, some climate models share a common lineage and in turn share common biases (Knutti et al. 2013).

Most GCMs reproduce annual cycles of regional averaged precipitation (Fig. 4a) reasonably well, even though the inter-model difference is large. They display much lower capabilities to reproduce spatial patterns of the mean and IAV of SMS mean precipitation (Fig. 4b,c) in spite of the higher resolution of recent versions and the introduction and improved representation of complex physical processes (Taylor et al. 2012). This fact underscores the need for improved understanding of underlying atmospheric processes - especially in mountainous regions - and for corresponding improvements in the models. The IAV of precipitation depends to a large degree on the horizontal resolution of the models (Giorgi 2002). The inability of GCMs to reproduce the spatial distribution of precipitation at regional levels is also described in reports of previous studies (Turner \& Annamalai 2012, Sperber et al. 2013, Su et al. 2013, Sharmila et al. 2015). Most of the models show a wet bias over steep topography (Mehran et al. 2014). About $66 \%$ of models show a wet bias. The rest of the models show a dry bias over the CHR (Table 3). Large biases in models are associated with convective parameterization schemes (Sabeerali et al. 2015). However, it is extremely difficult to identify a single factor explaining what makes a model good 


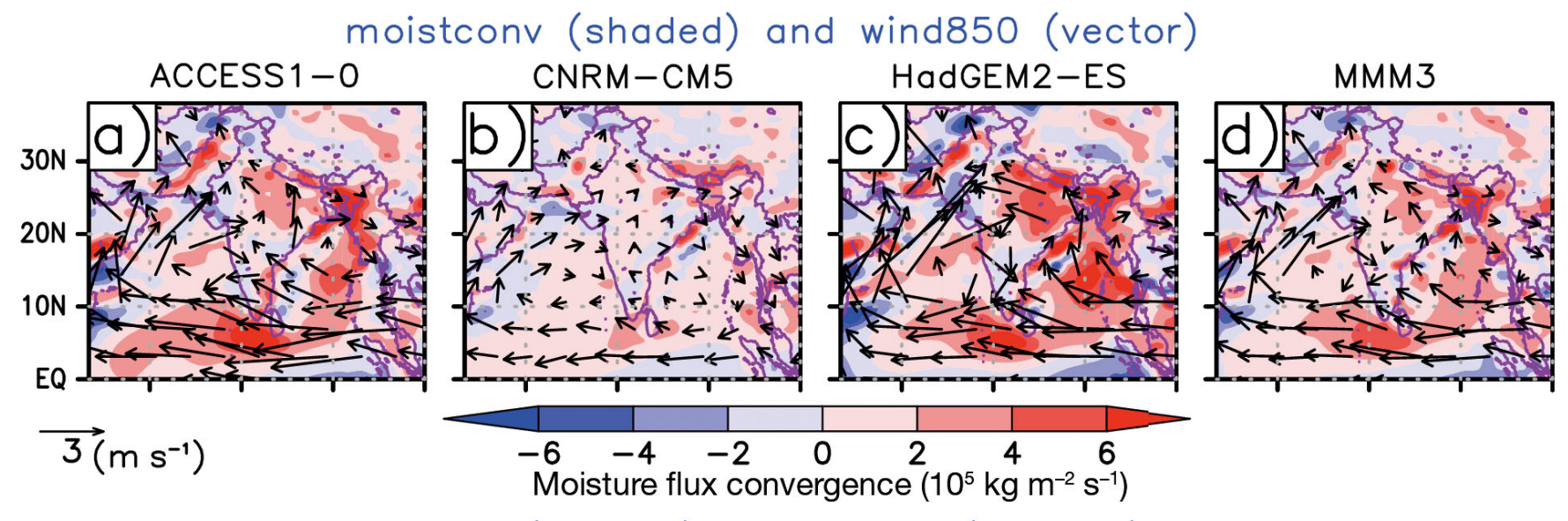

w500 (shaded) and sh850 (contour)
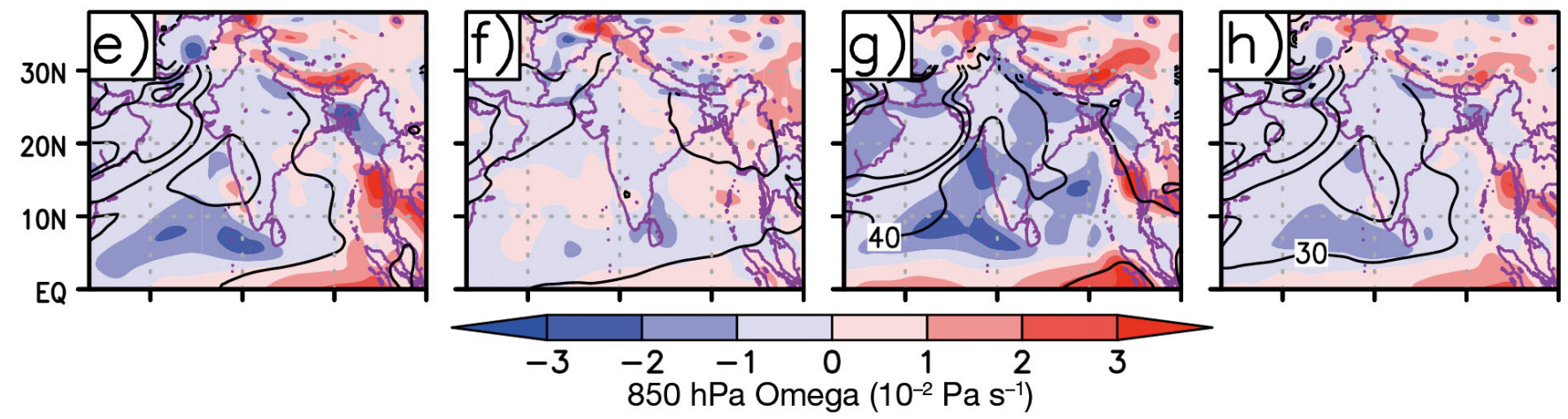

temp200 (shaded) and wind200 (vector)
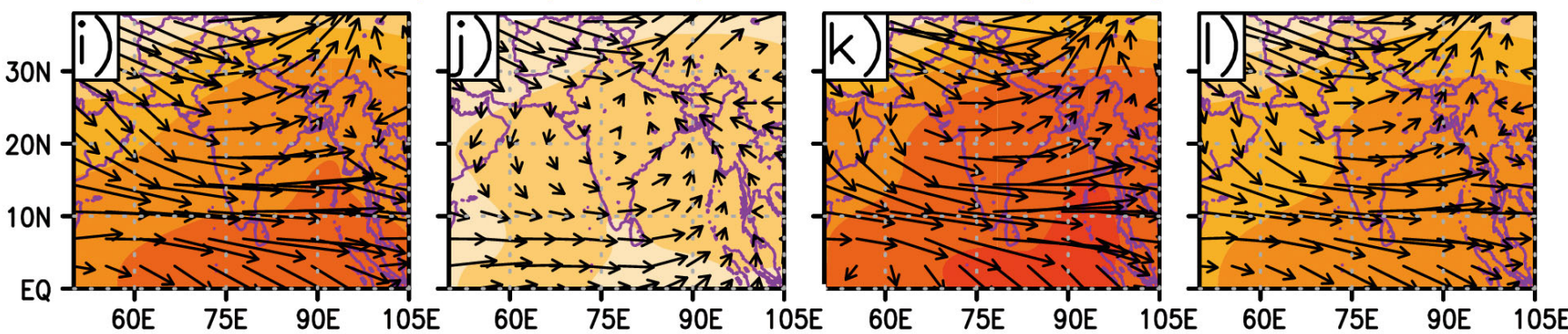

$\overrightarrow{4}\left(\mathrm{~m} \mathrm{~s}^{-1}\right)$

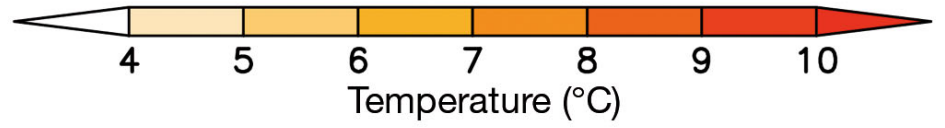

Fig. 13. Projected changes in the SMS mean state during 2070-2099 under RCP8.5 (a-d) vertically integrated (surface to $300 \mathrm{hPa}$ ) moisture flux convergence (color) and wind at $850 \mathrm{hPa}$ (vector); (e-h) omega at $500 \mathrm{hPa}$ (color) and specific humidity (contour interval: $10 \%$, negative value is denoted by dashed contour and positive value is denoted by solid contour); (i-l) temperature (color) and wind at $200 \mathrm{hPa}$ (vector). Projected changes are computed as $\left(\mathrm{Mean}_{\text {Future }}-\mathrm{Mean}_{\text {Present }}\right)$ except for the change in specific

humidity. Changes in specific humidity are computed as $\left(100 \times\left(\operatorname{Mean}_{\text {Future }}-\mathrm{Mean}_{\text {Present }}\right) / \mathrm{Mean}_{\text {Present }}\right)$

or bad in complex terrain (Fig. 4, Table 3) (Su et al. 2013, Palazzi et al. 2015). Past evidence shows that high-resolution models perform better than coarseresolution models through enhanced representation of topography and circulation (e.g. Fennessy et al. 1994, Rajendran et al. 2013). Our analysis shows that slight improvements in model resolution might not reduce model errors. For example, resolutions of
CCSM4, CESM1-BGC, CESM1-CAM5, and CMCC$\mathrm{CM}$ are finer than those of HadGEM2 models, but the former do not outperform the HadGEM2 models (Fig. 4, Table 2). Nevertheless, it is noteworthy that the spatial pattern of SMS precipitation is poorly reproduced by coarse resolution $\left(\geq 2.5^{\circ}\right.$ longitude) models. Similarly, it is apparent from the 3 HadGEM2 models (AO, CC, and ES), that differ from 
each other in the extent to which they incorporate complex physical processes, that improved representation of these processes does not improve model capability to a marked degree (The HadGEM2 Development Team 2011). In fact the improvement in bias is much less than the systematic mean bias. These results highlight that high-resolution (a few kilometers) models with improved physical parameterization schemes of physical processes are needed to obtain a reasonable spatial distribution (Rajendran et al. 2013).

Among the 38 GCMs, only 6 GCMs (ACCESS1.0, CNRM-CM5, EC-ERATH, HadGEM2-AO, HadGEM2-CC, and HadGEM2-ES) fulfill our criteria for 'superior' models. This result suggests that improved understanding of governing physical processes, and corresponding improvements in models, are required in order to simulate precipitation over mountainous regions realistically. HadGEM2-AO and HadGEM2CC were omitted in this study of precipitation projections because their skill in reproducing precipitation characteristics is lower or nearly equal to HadGEM2-ES for the present climate. Our results show agreement with past studies (Lee \& Wang 2014, Prasanna 2016). It is particularly interesting that 3 of the 4 selected 'best models' (ACCESS1.0, CNRMCM5, and HadGEM2-ES) are also recommended as the best models for South Asia (Prasanna 2016), as well as for global (Lee \& Wang 2014) monsoon assessment. However, the choice of the reference dataset and methodology affect the skill of the models.

Best models and MMMs project an increase in SMS mean precipitation in all future periods under RCP4.5 and RCP8.5. Model agreement and statistical significance are higher for mid-future and far-future periods. Unlike mean precipitation, model projections of changes in the variability of precipitation are not consistent for all future periods. However, projected change in IAV in the far-future period (20702099) under RCP8.5 is consistent among models, and is greater than the mean change. MMM4 projects an approximate $20 \%$ increase in mean SMS precipitation in this period. The increase in mean precipitation might be attributed to an increase in the moisture flux convergence, in turn attributable to the increase in the water holding capacity of the atmosphere in a warming environment (Turner \& Annamalai 2012, Sharmila et al. 2015, Prasanna 2016), enhancement of climatological low-level monsoon flow over the Arabian Sea (Ogata et al. 2014), and increased convective activity. However it is slightly offset by weakened easterly winds over the Arabian Sea and central India in the upper troposphere caused by warming of the Indian Ocean (Fig. 13). In fact, IAV of CHR precipitation is largely dominated by the Pacific Ocean sea surface temperature, i.e. ENSO). The ENSOmonsoon relation is projected to weaken over time (Li \& Ting 2015). However, simulation of ENSO by CMIP5 models is extremely uncertain (Turner \& Annamalai 2012, Jha et al. 2014).

Moderate to heavy precipitation days are projected to increase in the far-future period under RCP8.5, whereas light precipitation days are projected to decrease. However, regional uncertainty does exist. The projected increase of moderate to heavy rainfall might be related to increased flow from the Arabian Sea, increased moisture attributable to warming, and/or increased convective activity over the study region (Fig. 13) (Houze et al. 2007). The decrease in light rainfall might be attributable to a shift in daily precipitation amounts to higher rainfall categories. Furthermore, the frequency and length of active monsoon spells is consistently projected to increase in future periods, which might be attributed to enhanced low level circulation, increased convective activities, and/or moisture attributable to warming (Fig. 13). Our results related to extreme precipitation show good agreement with those of earlier studies (Panday et al. 2015, Sharmila et al. 2015, Kitoh \& Endo 2016, Wu et al. 2017).

The results show that increased mean precipitation and variability in precipitation are largely the result of increased frequency of moderate to heavy precipitation days and active spells. Our analyses show that more frequent and prolonged intense precipitation might occur in the future, which might strongly and adversely affect society if suitable adaptation measures are not planned and implemented.

Thorough analyses are necessary, however, to investigate the physical processes responsible for spatial and temporal variability of precipitation, and to evaluate how these processes are reproduced in climate simulations. As described herein, we did not perform analyses to ascertain the reasons behind the poor capability of models to simulate the spatial and temporal distribution of CHR SMS precipitation. Nor did we investigate possible causes of projected changes in precipitation characteristics, which might be related to numerous simulated variables. These matters are left as subjects for future work.

\section{CONCLUSIONS}

Precipitation over the Himalayas is highly variable both temporally and spatially. A major challenge 
faced by climate models is to simulate the spatial and temporal variability of precipitation over such mountainous regions. This study documents the capabilities of 38 global climate models participating in CMIP5 to simulate spatiotemporal variability of summer monsoon season precipitation over the central Himalayas under the present climate. Additionally, it reveals the projected changes in future seasonal mean and extreme precipitation under warming scenarios based on systematically selected best models and their MMM. Most of the models can simulate the mean annual cycle reasonably well. However, the inter-model spread is extremely large during the monsoon season. Realistic simulation of spatial distribution of the mean monsoon season precipitation and its IAV is problematic. Few models are successful in reproducing spatial and temporal variability reasonably well. Poor capabilities of models in simulating spatial patterns might be linked to coarse model resolutions and convective parameterization schemes.

We applied the 4 best models, based on their capabilities to reproduce the annual cycle, spatial patterns of monsoon season mean precipitation and its IAV, to study the future evolution of monsoon season precipitation under warming scenarios RCP4.5 and RCP8.5. However, the best models and their MMMs show considerable biases relative to observed precipitation and the inter-model spread is large.

All the best models and their MMM consistently indicate increases in monsoon season precipitation in future periods. Intensification is greater in the core monsoon months of July and August. Projected mean monsoon season precipitation increases gradually from near-future to far-future periods under both warming scenarios. MMM4 projects an increase in mean precipitation by $20 \%$ in a far-future period under RCP8.5. In addition, all models project an increase in IAV in far-future periods under RCP8.5. However, model agreement is poor for projected changes in variability for near-future and mid-future periods. Similarly, differences among the best models are apparent in the regional spatial distribution of projected changes, particularly IAV, which reflects the uncertainty of future projection.

Analysis of model projections of the occurrence of extreme weather events suggests that the projected increase in monsoon season mean precipitation is exacerbated by consistent intensification of moderate to heavy precipitation days, and projected increases in the frequency and length of active spells of monsoons under RCP8.5. The projected increase in seasonal mean precipitation might be attributable to increased moisture flux convergence, enhanced low- level wind from the Arabian Sea and increased convective activities associated with enhanced moisture due to warming. However, thorough studies of other variables should be undertaken to explore other possible thermodynamic and dynamic causes of precipitation change under warming scenarios.

Acknowledgements. The authors thank the Editor and 2 anonymous reviewers for their constructive comments. This study was partly supported by Social Implementation Program on Climate Change Adaptation Technology (SI-CAT) of Ministry of Education, Culture, Sports, Science and Technology (MEXT), Japan. I.K. and M.R.A. express sincere gratitude to MEXT for this scholarship. The authors would like to acknowledge the developers of the CMIP5 model outputs and the gridded observed precipitation datasets: APHRODITE, CPC, CRU, and GPCC.

\section{LITERATURE CITED}

Ageta Y, Naito N, Nakawo M, Fujita K, Shankar K, Pokhrel AP, Wangda D (2001) Study project on the recent rapid shrinkage of summer-accumulation type glaciers in the Himalayas, 1997-1999. Bull Glaciol Res 18:45-49

Alves JMB, Vasconcelos FC Junior, Chaves RR, Silva EM, and others (2016) Evaluation of the AR4 CMIP3 and the AR5 CMIP5 model and projections for precipitation in Northeast Brazil. Front Earth Sci 4:44

Andermann C, Bonnet S, Gloaguen R (2011) Evaluation of precipitation data sets along the Himalayan front. Geochem Geophys Geosyst 12:Q07023

Anders AM, Roe GH, Hallet B, Montgomery DR, Finnegan NJ, Putkonen J (2006) Spatial patterns of precipitation and topography in the Himalaya. Spec Pap Geol Soc Am 398:39-53

Annamalai H, Hamilton K, Sperber KR (2007) The South Asian summer monsoon and its relationship with ENSO in the IPCC AR4 simulations. J Clim 20:1071-1092

Baidya SK, Shrestha ML, Seikh MM (2008) Trends in daily climatic extremes of temperature and precipitation in Nepal. J Hydrol Meteorol 5:38-51

* Barros AP, Kim G, Williams E, Nesbitt SW (2004) Probing orographic controls in the Himalayas during the monsoon using satellite imagery. Nat Hazards Earth Syst Sci $4: 29-51$

* Beniston M (2003) Climatic change in mountain regions: a review of possible impacts. Clim Change 59:5-31

Bi D, Dix M, Marsland SJ, O'Farrell S and others (2013) The ACCESS coupled model: description, control climate and evaluation. Aust Meteorol Oceanogr J 63:41-64

* Chadwick R, Boutle I, Martin G (2013) Spatial patterns of precipitation change in CMIP5: why the rich do not get richer in the tropics. J Clim 26:3803-3822

Chalise SR (2002) Management of water resources for poverty alleviation in the Hindu-Kush Himalayas. In: Rees G (ed) Hindu Kush-Himalayan FRIEND 20002003. United Kingdom contribution to the International Hydrological Programme (IHP) of UNESCO. IHP-VI Technical Documents in Hydrology 68. UNESCO, Paris, p 27-34

Chen M, Xie P, Janowiak JE, Arkin PA (2002) Global land recipitation: a 50-yr monthly analysis based on gauge observations. J Hydrometeorol 3:249-266

Collins M, Rao AK, Ashok K, Bhandari S, and others (2013) 
Observational challenges in evaluating climate models. Nat Clim Chang 3:940-941

Dahal RK (2012) Rainfall-induced landslides in Nepal. Int J Erosion Control Eng 5:1-8

*Dahal RK, Hasegawa S (2008) Representative rainfall thresholds for landslides in the Nepal Himalaya. Geomorphology 100:429-443

Duan K, Yao T, Thompson LG (2006) Response of monsoon precipitation in the Himalayas to global warming. J Geophys Res Atmos 111:D19110

Duan A, Hu J, Xiao Z (2013) The Tibetan plateau summer monsoon in the CMIP5 simulations. J Clim 26:7747-7766

Fennessy MJ, Kinter JL III, Kirtman B, Marx L and others (1994) The simulated Indian monsoon: a GCM sensitivity study. J Clim 7:33-43

Gadgil S, Joseph PV (2003) On breaks of the Indian monsoon. Proc Indian Acad Sci (Earth Planet Sci) 112: 529-558

Giorgi F (2002) Dependence of the surface climate interannual variability on spatial scale. Geophys Res Lett 29

Goswami BN (2011) South Asian monsoon. In: Lau WKM, Waliser DE (eds) Intraseasonal variability in the atmosphere-ocean climate system, 2nd edn. Springer, Berlin, p 21-72

Harris I, Jones PD, Osborn TJ, Lister DH (2014) Updated high-resolution grids of monthly climatic observations the CRU TS3.10 Dataset. Int J Climatol 34:623-642

Houze RA Jr, Wilton DC, Smull BF (2007) Monsoon convection in the Himalayan region as seen by the TRMM precipitation radar. Q J R Meteorol Soc 133:1389-1411

Inoue T, Ueda H (2011) Delay of the first transition of Asian summer monsoon under global warming condition. Sci Online Lett Atmos 7:81-84

IPCC (2013) Climate change 2013: the physical science basis. Contribution of Working Group I to the fifth assessment report of the Intergovernmental Panel on Climate Change. Cambridge University Press, Cambridge

Jha B, Hu ZZ, Kumar A (2014) SST and ENSO variability and change simulated in historical experiments of CMIP5 models. Clim Dyn 42:2113-2124

Jourdain NC, Sen Gupta A, Taschetto AS, Ummenhofer CC, Moise AF, Ashok K (2013) The Indo-Australian monsoon and its relationship to ENSO and IOD in reanalysis data and the CMIP3/CMIP5 simulations. Clim Dyn 41: 3073-3102

Karki R, Hasson S, Schickhoff U, Scholten T, Böhner J (2017) Rising precipitation extremes across Nepal. Climate (Basel) 5:4

Kitoh A, Endo H (2016) Changes in precipitation extremes projected by using a $20-\mathrm{km}$ mesh global atmospheric model. Weather Clim Extrem 11:41-52

Knutti R, Masson D, Gettelman A (2013) Climate model genealogy: generation CMIP5 and how we got there. Geophys Res Lett 40:1194-1199

Kobayashi S, Ota Y, Harada Y, Ebita A and others (2015) The JRA-55 reanalysis: general specifications and basic characteristics. J Meteorol Soc Jpn 93:5-48

Krishnamurthy V, Shukla J (2000) Intraseasonal and interannual variability of rainfall over India. J Clim 13: 4366-4377

Kumar S, Merwade V, Kinter JL, Niyogi D (2013) Evaluation of temperature and precipitation trends and long-term persistence in CMIP5 twentieth-century climate simulations. J Clim 26:4168-4185

Lang TJ, Barros AP (2002) An investigation of the onsets of the 1999 and 2000 monsoons in central Nepal. Mon Weather Rev 130:1299-1316
Lee JY, Wang B (2014) Future change of global monsoon in the CMIP5. Clim Dyn 42:101-119

Li X, Ting M (2015) Recent and future changes in the Asian monsoon-ENSO relationship: natural or forced? Geophys Res Lett 42:3502-3512

Kin R, Zhou T, Qian Y (2014) Evaluation of global monsoon precipitation changes based on five reanalysis datasets. J Clim 27:1271-1289

McBride JL, Ebert EE (2000) Verification of quantitative precipitation forecasts from operational numerical weather prediction models over Australia. Weather Forecast 15: 103-121

* Mehran A, Aghakouchak A, Phillips TJ (2014) Evaluation of CMIP5 continental precipitation simulations relative to satellite-based gauge-adjusted observations. J Geophys Res Atmos 119:1695-1707

Menon N (2009) Rainfall uncertainty and occupational choice in agricultural households of rural Nepal. J Dev Stud 45:864-888

Menon A, Levermann A, Schewe J, Lehmann J, Frieler K (2013) Consistent increase in Indian monsoon rainfall and its variability across CMIP-5 models. Earth System Dynamics 4:287-300

Mirza MMQ (2011) Climate change, flooding in South Asia and implications. Reg Environ Change 11:95-107

Mishra V (2015) Climatic uncertainty in Himalayan water towers. J Geophys Res Atmos 120:2689-2705

* Mishra V, Kumar D, Ganguly AR, Sanjay J, Mujumdar M, Krishnan R, Shah RD (2014) Reliability of regional and global climate models to simulate precipitation extremes over India. J Geophys Res Atmos 119:9301-9323

Nayava JL (1980) Rainfall in Nepal. The Himalayan Review $12: 1-18$

Ogata T, Ueda H, Inoue T, Hayasaki M, and others (2014) Projected future changes in the Asian monsoon: a comparison of CMIP3 and CMIP5 model results. J Meteorol Soc Jpn 92:207-225

* Palazzi E, von Hardenberg J, Provenzale A (2013) Precipitation in the Hindu-Kush Karakoram Himalaya: observations and future scenarios. J Geophys Res Atmos 118: 85-100

Palazzi E, von Hardenberg J, Terzago S, Provenzale A (2015) Precipitation in the Karakoram-Himalaya: a CMIP5 view. Clim Dyn 45:21-45

*Panday PK, Thibeault J, Frey KE (2015) Changing temperature and precipitation extremes in the Hindu KushHimalayan region: an analysis of CMIP3 and CMIP5 simulations and projections. Int J Climatol 35:3058-3077

Panthi J, Dahal P, Shrestha ML, Aryal S, and others (2015) Spatial and temporal variability of rainfall in the Gandaki River basin of Nepal Himalaya. Climate (Basel) 3:210-226

* Prakash S, Mitra AK, Momin IM, Rajagopal EN, and others (2015) Seasonal intercomparison of observational rainfall datasets over India during the southwest monsoon season. Int J Climatol 35:2326-2338

* Prasanna V (2016) Assessment of South Asian summer monsoon simulation in CMIP5-coupled climate models during the historical period (1850-2005). Pure Appl Geophys 173:1379-1402

Rajbhandari R, Shrestha AB, Nepal S, Wahid S (2016) Projection of future climate over the Koshi River basin based on CMIP5 GCMs. Atmos Clim Sci 6:190-204

Rajeevan M, Gadgil S, Bhate J (2010) Active and break spell of the Indian summer monsoon. J Earth Syst Sci 119: $229-247$

Rajendran K, Sajani S, Jayasankar CB, Kitoh A (2013) How dependent is climate change projection of Indian sum- 
mer monsoon rainfall and extreme events on model resolution? Curr Sci 104:1409-1418

Ramesh KV, Goswami P (2014) Assessing reliability of regional climate projections: the case of Indian monsoon. Sci Rep 4:4071

Rangwala I, Sinsky E, Miller JR (2013) Amplified warming projections for high altitude regions of the northern hemisphere mid-latitudes from CMIP5 models. Environ Res Lett 8:024040

Roxy MK, Ritika K, Terray P, Murtugudde R, Ashok K, Goswami BN (2015) Drying of Indian subcontinent by rapid Indian Ocean warming and a weakening land-sea thermal gradient. Nat Commun 6:7423

Sabeerali CT, Rao SA, Dhakate AR, Salunke K, Goswami BN (2015) Why ensemble mean projection of south Asian monsoon rainfall by CMIP5 models is not reliable? Clim Dyn 45:161-174

Schneider U, Becker A, Finger P, Meyer-Christoffer A, Ziese M, Rudolf B (2014) GPCC's new land surface precipitation climatology based on quality-controlled in situ data and its role in quantifying the global water cycle. Theor Appl Climatol 115:15-40

Sharmila S, Joseph S, Sahai AK, Abhilash S, Chattopadhyay $R$ (2015) Future projection of Indian summer monsoon variability under climate change scenario: an assessment from CMIP5 climate models. Global Planet Change 124: 62-78

Shrestha ML (2000) Interannual variation of summer monsoon rainfall over Nepal and its relation to Southern Oscillation Index. Meteorol Atmos Phys 75:21-28

Shrestha AB, Aryal R (2011) Climate change in Nepal and its impact on Himalayan glaciers. Reg Environ Change 11: 65-77

Shrestha AB, Wake CP, Dibb JE, Mayewski PA (2000) Precipitation fluctuations in the Nepal Himalaya and its vicinity and relationship with some large scale climatological parameters. Int J Climatol 20:317-327

Sigdel M, Ikeda M (2010) Spatial and temporal analysis of drought in Nepal using standardized precipitation index and its relationship with climate indices. J Hydrol Meteorol 7:59-74

Sigdel M, Ikeda M (2012) Summer monsoon rainfall over Nepal related with large-scale atmospheric circulations. J Earth Sci Clim Change 3:112

Smith TM, Reynolds RW, Peterson TC, Lawrimore J (2008) Improvements to NOAA's historical merged land-ocean temp analysis (1880-2006). J Clim 21:2283-2296

Sperber KR, Palmer TN (1996) Interannual tropical rainfall variability in general circulation model simulations associated with the atmospheric model intercomparison project. J Clim 9:2727-2750

Sperber KR, Annamalai H, Kang IS, Kitoh A, and others (2013) The Asian summer monsoon: an intercomparison of CMIP5 vs. CMIP3 simulations of the late 20th century. Clim Dyn 41:2711-2744

Editorial responsibility: Eduardo Zorita, Geesthacht, Germany
Su F, Duan X, Chen D, Hao Z, Cuo L (2013) Evaluation of the global climate models in the CMIP5 over the Tibetan Plateau. J Clim 26:3187-3208

* Taylor KE (2001) Summarizing multiple aspects of model performance in a single diagram. J Geophys Res 106: 7183-7192

Taylor KE, Stouffer RJ, Meehl GA (2012) An overview of CMIP5 and the experiment design. Bull Am Meteorol Soc 93:485-498

The HadGEM2 Development Team: Martin GM, Bellouin N, Collins WJ, Culverwell ID and others (2011) The HadGEM2 family of Met Office Unified Model climate configurations. Geosci Model Dev 4:723-757

* Tong K, Su F, Yang D, Zhang L, Hao Z (2014) Tibetan Plateau precipitation as depicted by gauge observations, reanalyses and satellite retrievals. Int J Climatol 34: 265-285

*Toreti A, Naveau P, Zampieri M, Schindler A and others (2013) Projections of global changes in precipitation extremes from Coupled Model Intercomparison Project Phase 5 models. Geophys Res Lett 40:4887-4892

* Turner AG, Annamalai H (2012) Climate change and the South Asian summer monsoon. Nat Clim Chang 2: 587-595

Turner AG, Inness PM, Slingo JM (2005) The role of the basic state in the ENSO-monsoon relationship and implications for predictability. QJR Meteorol Soc 131: 781-804

*Vellore RK, Krishnan R, Pendharkar J, Choudhury AD, Sabin TP (2014) On the anomalous precipitation enhancement over the Himalayan foothills during monsoon breaks. Clim Dyn 43:2009-2031

* Vellore RK, Kaplan ML, Krishnan R, Lewis JM, and others (2016) Monsoon-extratropical circulation interactions in Himalayan extreme rainfall. Clim Dyn 46:3517-3546

*Wang SY, Yoon JH, Gillies RR, Cho C (2013) What caused the winter drought in western Nepal during recent years? J Clim 26:8241-8256

Webster PJ, Magana VO, Palmer TN, Shukla J, Tomas RA, Yanai M, Yasunari T (1998) Monsoons: processes, predictability, and the prospects for prediction. J Geophys Res 103:14451

Wu J, Xu Y, Gao XJ (2017) Projected changes in mean and extreme climates over Hindu Kush Himalayan region by 21 CMIP5 models. Advances in Climate Change Research 8:176-184

$\mathrm{Xu}$ J, Grumbine RE, Shrestha A, Eriksson M, Yang X, Wang Y, Wilkes A (2009) The melting Himalayas: cascading effects of climate change on water, biodiversity, and livelihoods. Conserv Biol 23:520-530

*Yatagai A, Kamiguchi K, Arakawa O, Hamada A, Yasutomi N, Kitoh A (2012) APHRODITE: constructing a long-term daily gridded precipitation dataset for Asia based on a dense network of rain gauges. Bull Am Meteorol Soc 93: 1401-1415

Submitted: March 21, 2017; Accepted: October 19, 2017 Proofs received from author(s): February 27, 2018 